MENTOR PROGRAM DELIVERY

AND ACCOUNTABILITY: A MIXED

METHODS STUDY IN SOUTHWEST MISSOURI

\author{
A Dissertation \\ presented to
}

the Faculty of the Graduate School

at the University of Missouri-Columbia

In Partial Fulfillment

of the Requirements for the Degree

Doctor of Education

By:

ANGELA BOYER

Dr. Cornelius-White, Dissertation Supervisor

DECEMBER 2017 
The undersigned, appointed by the dean of the Graduate School, have examined the dissertation entitled

\section{MENTOR PROGRAM DELIVERY AND ACCOUNTABILITY: A MIXED METHODS STUDY IN SOUTHWEST MISSOURI}

presented by Angela Boyer

a candidate for the degree of doctor of education,

and hereby certify that, in their opinion, it is worthy of acceptance.

Dr. Cornelius-White

Dr. MacGregor

Dr. Cormier

Dr. Goodwin 


\section{DEDICATION}

First and foremost, I would like to acknowledge my husband, Jeremy, and his unwavering support of my educational goals. Throughout our marriage, he has supported my dreams of furthering my knowledge, sometimes while putting his own goals on pause and moving across states for me to pursue my passion. I am also thankful for the opportunity to create a strong model focused on the importance of education for our son, Coltyn. The doctoral learning journey has been an adventure of finding strength and balance while taking on new learning, and both of my boys have been my greatest cheerleaders throughout the process. 


\section{ACKNOWLEDGEMENTS}

Without a doubt, the professors of the ELPA program, my advisor Dr. Cornelius-White, and my cohort nine members have all directly impacted a successful program completion for me, but more importantly, have created a network of supports for me as a continued learner. The professors of the ELPA program, especially Dr. MacGregor, Dr. Baumann, and Dr. T.C. Wall, provided a multitude of learning opportunities, which pushed me further in my thinking, scholarly writing, and reflection. Dr. Cornelius-White has been both a sounding board and a check-in partner throughout the dissertation process and without his continued patience and guidance, I would not have gained the confidence needed to complete a mixed methods study on mentoring. Additional levels of confidence and support came from the relationships I built with cohort nine members, especially Nicole Holt, Dr. Jeffry Wead, and Rob Kroll- thank you for providing laughter during late night writing, feedback when I most needed it, hugs following our presentations, and conversations filled with positivity and thoughtful ideas.

Outside of the doctoral program, I could not have asked for a better network of supporters both in Nebraska and Ozark. To all of my Belmont colleagues, especially my principal leaders who believed in growing me, thank you as you were one of the first important stepping stones in my journey as an educator. I am beyond thankful my time at Belmont created lasting friendships with Christa Kimbrough, Meka Bauer, and Jamie Cook, who remain part of my cheer squad with the motto: "She believed she could, so she did." My cheering squad only grew larger when I became a member of Ozark's coaching team. My colleagues Amy Dunn and Ann Poivre have been constant supports, along with Dr. Karen Scott. Thank you for your check-ins, for listening to me discuss mentoring, and for helping me keep my coaching head above water during my 
doctoral journey. These relationships plus my Sweem and Boyer family supports have made a world of difference throughout the program. 


\section{TABLE OF CONTENTS}

ACKNOWLEDGEMENTS ....................................................

\section{Chapter}

1. INTRODUCTION TO DISSERTATION ............................

Background of Study ............................................................2

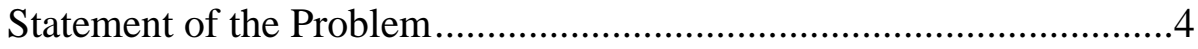

Purpose of Study ................................................................. 6

Research Questions .......................................................... 8

Conceptual Framework ..............................................................

Design of the Study............................................................ 14

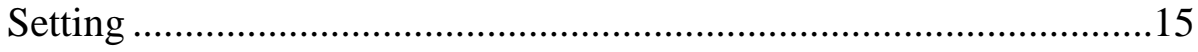

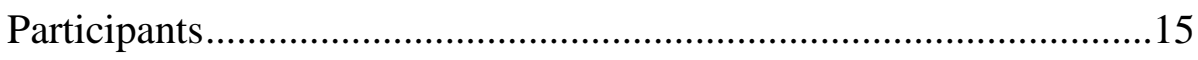

Data Collection Tools ................................................................ 16

Data Analysis ..................................................................... 17

Limitations.............................................. 18

Assumptions..................................................19

Significance of the Study....................................19

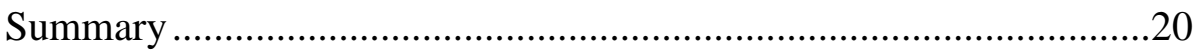

\section{ORGANIZATIONAL AND LEADERSHIP CONTEXT FOR STUDY ...21}

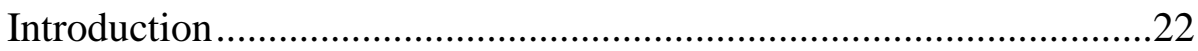

Organizations Focused on Mentoring..........................23

Organizational Analysis ........................................................24

Mentoring through the Structural Lens ..........................................24 
Mentoring through the Human Resource Lens....................27

Mentoring through the Political Lens..............................28

Leadership Analysis........................................29

Mentors as Servant Leaders......................................29

Communication........................................... 30

Organizational Backgrounds of the Present Study...................31

Implications for Research .......................................................33

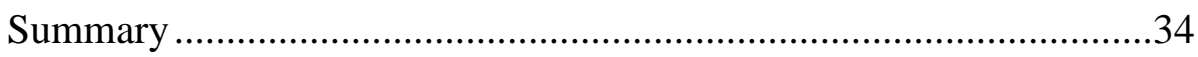

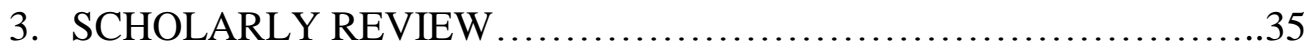

Introduction................................................

The New Teacher Center......................................38

Mentoring Across the States and Countries........................43

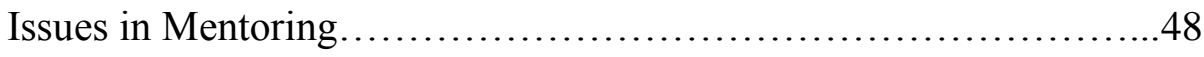

Training Mentor Teachers...................................52

Monitoring Mentor Teachers .......................................................56

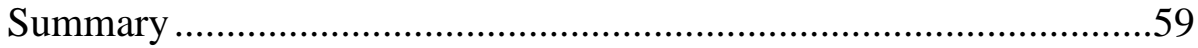

4. CONTRIBUTION TO PRACTICE...............................60

Executive Summary.......................................61

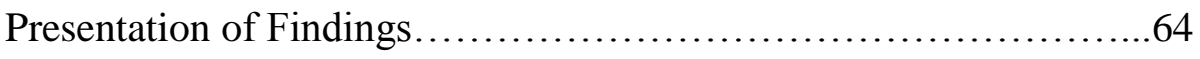

5. CONTRIBUTION TO SCHOLARSHIP..............................88

References...............................................115

6. SCHOLARLY PRACTIONER REFLECTION ......................118

REFERENCES..................................................... 125 


\section{APPENDICES}

A. Informed Consent Mentor Leader Survey .............................................132

B. Mentor Leader Survey ..................................................................134

C. Informed Consent Mentor Teacher Survey ……………........................137

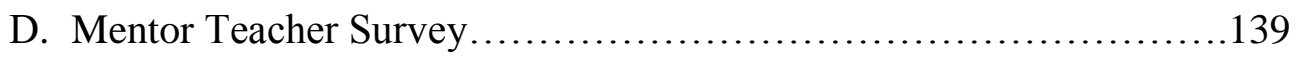

E. Informed Consent Mentor Teacher Focus Group....................142

F. Focus Group Interview Questions ....................................................143

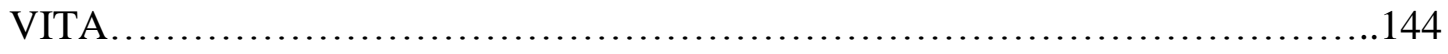


SECTION ONE:

INTRODUCTION TO DISSERTATION 


\section{Background of Study}

Since the 1960s and 1970s, formal mentoring programs emerged which included support and assistance for new teachers in "negotiating the uncertain terrain of school policies and procedures" (Ganser, 2005, p. 7). While mentoring programs have continued to be influenced by evolving professional standards and policies for teacher induction, Ganser (2005) specifically noted “...during the past fifteen years, the significance of mentoring programs as part of the profession of teaching has grown exponentially" (p. 14). With an increase in mentor activity rising from $40 \%$ to $89.4 \%$ since the 1990s (Feiman-Nemser, 2012), current research shows more than half of the states require teachers to participate in mentoring or induction programs to some degree (The New Teacher Center, 2012).

Ingersoll (2012) found $91 \%$ of beginning teachers reported they received support from an induction program as of 2008 , however, the variance in the types of mentoring supports is a cause for dialogue in education (Ingersoll, 2012). Casey and Claunch (2005) also noted "While mature, comprehensive, and successful programs exist in some states and large school districts, the mentoring of beginning teachers has not been fully institutionalized in public education" (p. 98). A recent policy review of induction and mentoring programs by The New Teacher Center in 2012 addresses the current status of

mentoring in each state. The report not only provided a state-by-state analysis of current mentor practices but also highlighted current trends in ten criteria outlined by The New Teacher Center. A major finding from the review of state policy showed, "multi-year induction programs accelerate the professional growth of new teachers, reduce the rate of 
new teacher attrition, provide a positive return on investment, and improve student learning” (Goldrick, Osta, Barlin, \& Burn, 2012, p. iii).

Additionally, The New Teacher Center (2012) noted, "comprehensive state policies have a broad influence on supporting the development of local induction programs" (p. vi). The premise for the ten criteria utilized in the policy review indicated states meeting more of the criteria would "raise the likelihood that every new educator receives a sufficient level of induction and mentoring support...” and therefore benefit from "enhanced teacher effectiveness" (p. vi). The first two criteria advocate for all teachers and school administrators to receive two years of induction support. Criterion three states a requirement for formal program standards to guide the design and operation of mentoring programs. Criteria four through six focus on rigorous selection and ongoing training of mentor teachers, in addition to considerations about the assignments and caseloads of mentor teachers. Criterion seven is focused on the program elements, including considerations for contact time between mentors and new teachers, formative assessment of teaching practice, and classroom observations. Criterion eight suggests funding as a component for supporting induction programs. Finally, criteria nine and ten focus on accountability of the education and program, and suggests assessing or monitoring program quality should occur through evaluation, surveys, site visits, and other tools.

In the New Teacher Center's report (2012), Missouri's teacher induction policies were reviewed and several areas of strength were highlighted in regards to current requirements and recommendations for mentoring. Currently, Missouri requires both teachers and administrators to receive induction support for the first two years in the 
profession in the form of a teacher-driven mentor program (New Teacher Center, 2012). Since 2010-2011, the state Department of Elementary and Secondary Education (DESE) has also been required to develop formal program standards in Missouri. As a result, Missouri is one of fifteen states requiring foundational mentor training and ongoing professional development for mentor teachers. Further, Missouri's criteria includes a minimum requirement of three years of experience in the profession to be eligible to mentor new teachers. Missouri is one of the many states with minimal expectations regarding the time mentors will spend with their mentee. Furthermore, state policy aims to protect mentors from additional duties, which could interfere with time focused on mentoring. Missouri addresses classroom observations in the policy by recognizing sufficient time is necessary to observe teaching and should be accounted for thorough release time and schedule coordination.

\section{Statement of the Problem}

Throughout history, one of the most common forms of mentoring has been an informal buddy system of providing technical advice and emotional support for new teachers by an experienced teacher (Feiman-Nemser, 2012). Unfortunately, research has shown the buddy system model lacks key components of stronger mentor methods such as observations including feedback or opportunities for reflection on practices between the mentor and mentee. When mentoring lacks effective design components, it can produce negative results (Feiman-Nemser, 2012). Further, Casey and Claunch (2005) indicated mentors must build knowledge about adult learning and be able to extend the knowledge of the mentee through conversations, which include listening and 
reflecting. In addition to building an understanding of adult learners, Grossman and Davis (2012) confirmed:

To be effective, mentors require training and ongoing support to develop specific skills in assisting new teachers- for example, developing working relationships with adults, determining the strengths and needs of a new teacher, helping teachers set meaningful goals, and providing constructive feedback on instruction. (p. 55)

Ganser (2005) noted the effective partnering of a mentor and mentee can "positively impact the career trajectory of new teachers for a lifetime" (p. 15). However, even with a rise in mentoring supports, research by Athanases, et al. (2008) found induction programs in the United States "rest on impoverished models" (p. 745). Further, research by Ingersoll (2002) has indicated one-third of beginning teachers do not remain in the profession beyond the first three years of service and $43 \%$ of beginning teachers identified a lack of adequate support as a key factor impacting the first three years in the profession. In 2012, The New Teacher Center's policy review of induction and mentoring programs found there are only three states currently meeting the majority of the mentoring criteria, as outlined by The New Teacher Center: Connecticut, Delaware, and Iowa.

The New Teacher Center's policy review indicated Missouri does not meet the elements of criterion seven (program delivery) and is not considered an exemplary example of criterion ten (program accountability). Additionally, the policy review reported many states are trying to support induction policy criteria, however, necessary funding or training elements needed to have successful programs are often missing 
supports. Although the state of Missouri does not provide funding to support mentoring programs, districts are required to offer a program in order for teachers to receive a career continuous professional certificate (New Teacher Center, 2012). For this reason, a study designed to investigate the delivery of mentoring programs and accountability measures could support states, such as Missouri, in shifting to enhance mentoring practices, and ultimately work towards meeting the majority of the criteria.

\section{Purpose of the Study}

With an increasing number of new teachers in need of mentors each year in education, there is a growing need for effective mentors who are knowledgeable about the subject(s) they are mentoring and who have the necessary skills for working with adult learners (Lieberman, Hanson, \& Gless, 2012). Similarly, Johnson and Ridley (2008) discuss mentoring as "dynamic, reciprocal, personal relationships in which a more experienced person (mentor) acts as a guide, role model, teacher, and sponsor of a less experienced person (protégé)" (p.xi). Both of these aspects are included in criteria four through six of The New Teacher Center's policy review which outline the need for mentors to gain the necessary skills to support their mentees, receive time to refine these skills, and employ strategies for building mentoring relationships. In addition to those aspects of mentoring, mentors need support conducting classroom observations and providing feedback tailored to the learning needs of their mentees (criterion seven).

One purpose of this study was to gain mentor perspectives on the supports received related to criterion seven. The location for the study involved several districts in the southwest region of Missouri. While Missouri is one of several states that does not quantify a minimum amount of contact time for mentor-mentee interactions, the 
standards include the element of release time for observations and a minimum requirement of three meetings each year. The New Teacher Center (2012) stated "Without sufficient time to develop a mentoring relationship characterized by frequent and substantive interactions, policy and programmatic intent is undermined and the likelihood of improved new teacher effectiveness and student achievement is greatly lessened" (p. 17). Further, the NTC recommends weekly protected time between 1.25 and 2.5 hours to allow for mentor and mentee interactions.

The New Teacher Center (2012) also stated a need to "raise expectations by articulating research-based program elements" as part of criterion seven (p.17). Currently, the Missouri mentor program standards do not specify the critical element of formative assessment. This standard, when implemented, could include the process of data collection and collaborative conversations between the mentor and mentee, allowing for discussion around research-based practices. The policy review indicated 16 states currently have this component in place and the importance of the implementation of this element as a means to impact individual teacher performance.

The final component of criterion seven is classroom observation, which NTC (2012) stated, "To observe intentionally and effectively, mentors should receive foundational training in data collection, analysis, and interpretation skills and obtain experience with classroom observation and formative assessment protocols that become the foundation of coaching" (p. 19). Missouri is one of 25 states that provides release time as a recommendation to allow for observations to occur for mentors and mentees. Additionally, class schedules for the mentor and mentee are recommended to align to allow for sufficient observation time. 
In addition to criterion seven, there was a need to study program accountability (criteria ten). This component includes the monitoring of mentor programs through the use of evaluation, surveys, site visits, and self-reports. The Missouri standards include recommendations on gathering feedback in the form of pre and post surveys as well as exit interviews. Since the 1990s, there has been a rise in evaluation techniques for reviewing and monitoring the quality of mentoring programs. These techniques have begun to include more about learning results and the impact of mentoring programs (Ganser, 2005). The New Teacher Center (2012) encouraged the leaders of mentor programs to evaluate existing program elements and identify shifts needed to better meet the needs of mentors and new teachers. Thus, another purpose for this study was to gather data about current accountability measures used by districts in Missouri.

\section{Research Questions}

Two research questions guided data collection and analyses in this study focused on mentoring. Both questions were addressed through mixed methods inquiry.

1. To what extent are elements of mentor program delivery (contact time, formative assessment, and classroom observation) and training for mentor teachers (perceptions) present in school districts across Southwest Missouri?

2. How are mentoring programs monitored across school districts in Southwest Missouri?

\section{Conceptual Framework}

Existing literature refers to mentors using a variety of metaphors, many of which lack guidance on what mentoring actually entails. An understanding of the roles and features of mentoring can help demonstrate the complex and dynamic relationship 
between adult learners. Descriptions of the role of the mentor, while often varied, have included providing classroom observations and feedback, engaging in discussion, locating materials and providing general information, and being a liaison for the mentee (Lieberman, Hanson, \& Gless, 2012). Schien (1978) described mentoring roles as being similar to a coach, developer of talent, opener of doors, or protector. Galvez-Hjornevik (1986) described mentors as trusted guides and counselors, while Borko (1986) used more traditional terms such as helper, peer, or support teacher. Additionally, George, Sims McLean, and Mayer (2007/2011) included aspects of mutual learning, exploration of similar values, and shared enjoyment in describing the importance of a life-changing mentor.

While the models for mentoring new teachers are complex and training opportunities for mentor teachers are varied, one of the consistent theories recognized in literature about mentoring is the connection to adult learning theory. With a primary focus in this study on the mentor teacher, Casey and Claunch's (2005) ideas about the need for recognizing the growth which occurs for the mentor teacher as they change from primarily being knowledgeable about content knowledge to gaining professional knowledge apply. The growth of mentor teachers can be identified through the application of five stages including predisposition, disequilibrium, transition, confidence, and efficacy. The predisposition stage begins with a classroom teacher who is willing to mentor as a means to generate growth by nurturing others and challenging themselves to improve. During the disequilibrium stage, the shift from teaching students to teaching adult learners begins to occur as the roles and responsibilities of being a mentor become clearer. The third stage known as the transition phase requires the mentor to expand their 
mentoring knowledge while developing mentor strategies and relationships with colleagues. Following the transition stage, mentors move into the confidence stage, where the shift to "facilitator of understanding" and recognition of growth both in the mentee and themselves occurs (Casey \& Claunch, 2005). Finally, the efficacy stage includes mentor teachers feeling they make a difference in their role while discovering a deeper understanding of effective teaching practices.

O'Neil (1981) further noted five stages involved in forming relationships between the mentor and mentee which include entry, trust building, encouragement or risk taking, the teaching of skills, and concern for professional standards. These stages combined with Fuller's (1969) stages for teacher development which included survival, competence, confidence, autonomy, and commitment were supports for Kram's (1983) theories about the developmental relationships created during mentoring which included four predictable phases. At the beginning of the mentoring relationship, the initiation phase provides an opportunity for mentors and mentees to learn about each other's style and preferences. At about the six months to a year time period, the mentoring may progress to the cultivation phase. This phase is an opportunity for the mentee to learn and advance their performance from the learning provided by the mentor. At this phase, the mentee is likely to gain the most knowledge and support within the organization from their mentor, which can last up to five years. Once the mentee begins to become more independent, the separation phase begins. This phase may include physical separation as changes in positions occur or supports are no longer as needed. The final redefinition phase is the phase that includes a change to a peer relationship where mutual supports between the mentor and mentee are likely to occur. 
Additional connections between adult learning theories and mentoring were supported by Levinson (1978). Levinson described mentoring as a “...model of adult conduct" and the "...acts of giving and receiving” (p.96). Furthermore, Levinson (1978) suggested focusing on the character of the relationship rather than the formality tied to mentor roles using more of a cyclical model of mentoring. In The New Teacher Center's (2012) expectations for interactions between mentors and mentees, criteria seven specifies interactions to include contact time, conversations about formative assessment, and classroom observations. More specifically, providing sufficient time and focused efforts on what the mentoring could look like is woven throughout criteria seven. According to The New Teacher Center (2012), “one of the program design elements most associated with impacts on teaching effectiveness and student learning is the frequency and duration of mentor-mentee contact time" (p. 17). Additionally, The New Teacher Center's expectations for formative assessment are grounded in the belief that, "Critical to teacher development is the practice of capturing and using assessment data to guide the support of beginning teachers" (NTC, 2012, p. 18).

\section{Contact Time}

The New Teacher Center (2012) suggests frequent and meaningful interactions to help maintain policy and program intentions. More specifically, contact time offers mentors and mentees opportunities to develop experiences focused on instruction either on a weekly, monthly, quarterly, or semester basis. Several states have either indicated specific contact time requirements or conditions for supporting this aspect for mentors and their mentees. According to NTC's (2012) study, North Carolina limits preparations, non-instructional duties, and additional assignments for new teachers to allow for contact 
time. NTC's (2012) findings about Maryland's contact time policy included the requirement of regularly scheduled meetings, observations, and co-teaching opportunities for the mentee with a skilled mentor. Additionally, Arkansas policy focused on weekly contact hours and 25 additional hours per semester while Kentucky has a minimum of 20 hours of classroom contact and 50 hours of outside of the classroom contact between the mentor and mentee (NTC, 2012). While many states have expectations for contact time between mentors and mentees, the use of full-release mentors have also shown to provide more of the necessary time for collaboration between new teachers and their mentors.

\section{Formative Assessment}

A skilled mentor can be the key to leading conversations about how to analyze data and collaboratively plan for the next steps of instruction. More specifically, the mentoring relationship can support The New Teacher Center's (2012) three elements for formative assessment, which include standards for best practice, criteria for measuring growth, and evidence of achievement. In California, induction programs require three similar elements in order to develop a collaborative plan to guide professional growth of the mentee through data collection focused on practices and tools to identify the progress. According to The New Teacher Center (2012), South Carolina requires a "mentor-guided formative assessment process," which can help the mentee focus on reflection of teaching, areas of need or concern, and aspects of professional development. While NTC noted at least 16 states have a focus on formative assessment aspects as part of induction, its importance is "...only really meaningful if it materializes at the core of the work of mentors and helps to impact individual teacher performance" (p. 18). 


\section{Classroom Observation}

Another critical aspect for supporting new teachers through mentoring is the element of classroom observation. The New Teacher Center's (2012) expectation for classroom observations includes, "A sustained cycle of repeated observations, feedback and discussion..." (p. 19). Further, the observations should be intentional, and mentors should have experience with protocols for data collection, analysis, and interpretation. According to NTC's policy review (2012), Delaware's induction expectations include a three-year framework with cycles of observations, post-observation meetings, video review, workshops, and self-reflections. Another induction example from West Virginia indicated mentor observations for one hour per week during the first half of the school year and then bi-weekly during the second part of the school year in addition to joint planning periods for the mentor and mentee. The New Teacher Center noted over half of the states require some level of classroom observations, but there is considerable variance across the states.

Overall, The New Teacher Center (2012) indicated nine states have induction program expectations for contact time, formative assessment, and classroom observations outlined to some degree. The goal for mentoring would be to utilize these elements to accelerate the effectiveness of the new teacher, but also develop the mentor teacher. Similarly, Lieberman, Hanson, and Gless (2012) described the purpose of mentoring programs as a support for "not only the growth of beginning teachers but also the growth of those who mentor" (p. xii). Gill (2010) noted if a mentoring relationship is working well, then both the mentee and mentor will learn. 


\section{Design of the Study}

For the purpose of this study, the researcher selected a convergent parallel mixed methods approach to study mentoring programs in select districts in the Southwest region of Missouri. Creswell (2014) stated “...in mixed methods research, investigators use both quantitative and qualitative data because they work to provide the best understanding of a research problem" (p.11). Further, in a convergent parallel design, qualitative and quantitative results are collected at about the same time (Creswell, 2014). Waterman and $\mathrm{He}$ (2011) noted mentoring research designs are typically comprised of quantitative data which is then analyzed through statistical measures. However, Waterman and He (2011) discussed research needed in the field of mentoring which goes beyond quantitative data and data which recognizes context and the complexity of mentoring. Consequently, the goal for data collected in this study was a mixed methods approach which included both closed and open-ended survey questions and focus group interviews.

Initially, a small sample group of mentor program leaders was surveyed to gather data on both research questions and documents were requested from each mentoring program in the selected districts. The researcher also hoped to gain access to mentor teachers within each participating district, with a request to survey mentor teachers who have mentored at least one teacher between the 2013-2014 and 2016-2017 school years. Additionally, mentor teachers who participate in the survey will have the option of participating in a focus group interview at each site, with a goal to gain additional qualitative data on both research questions. 


\section{Setting}

The researcher planned to collect and analyze data from a specific subset of districts in Missouri during data collection. For the purpose of this study, a setting within Southwest Missouri was selected due to the proximity of the researcher and to limit the sample size within one region. Further, the selected region included the researcher's current district of employment, District A. Due to the size of District A, additional districts were contacted to participate in the study which included District B and District C. This provided the researcher with three mentoring programs to study and potentially groups of mentor teachers at each district to participate in surveys and focus group interviews.

\section{Participants}

During the first survey portion of the study, one participant from each of the selected districts was contacted to participate in the study, with a total of four or more survey participants as the goal. The intended contact for the survey was the district employee(s) or department head(s) assigned to supervise mentoring or induction programs. Ganser (2005) noted it may be common for "... a director of instruction, curriculum supervisor, or manager of staff development..." to be responsible for a district's mentoring program (p. 5). The researcher planned to utilize the initial survey in order to gain data regarding which elements of mentoring program delivery and accountability are currently present in each of the respective programs. Additionally, these individuals may be the "gate-keepers" for providing existing documents and contacts to further support the study. The goal for collecting documents was to determine 
which elements of delivery and accountability were outlined in each districts' mentor program guidelines.

Directly following the initial survey responses, the researcher planned to have participating districts send an additional survey from the study to mentor teachers who have mentored at least one mentee between the 2013-2014 and 2016-2017 school years. The possible sample size for each district was estimated to contain between 10 and 30 mentor teachers during each of the four years of the study per site, with an overlap of some mentors who continue the mentoring role over the years. Both the mentor leader survey and the mentor teacher survey contained questions which were quantitative and qualitative in nature. Mentor teachers who participated in the study had the opportunity to participate in a focus group interview at each district site. The interviews probed for information regarding the delivery and monitoring of the mentoring programs in each district participating in the study. Merriam (2009) noted the importance of purposeful sampling to include people who are knowledgeable about the topic and encouraged groups which include six to ten participants. For this study, three groups of six to eight participants was the goal for collecting qualitative data.

\section{Data Collection Tools}

Data collection for this study was obtained through the analysis of two sets of survey responses, focus group interviews, and the review of available existing mentor program documents. Initial survey participation was requested using an online consent (Appendix A) and an electronic survey to gather information about both research questions (Appendix B). More specifically, the researcher used a 15-question survey primarily composed of close-ended questions with a few open-ended questions to gather 
information "from the people who are most likely to give the most accurate answers" (Fink, 2013, p.57). The survey began with questions which were easiest and most comfortable for participants to answer and continue with questions which were more subjective in style as suggested by Fink (2013). Following the initial survey of mentor leaders, mentor teachers from each district were contacted for participation in the study. The interested mentor teachers received an online consent (Appendix C) and an electronic survey consisting of 12 questions, both quantitative and qualitative in nature (Appendix D).

Additionally, qualitative data was collected utilizing focus group interviews of mentor teachers. The goal of the focus group interview questions was to gain insights about both research questions from mentor teachers themselves. An interview consent form (Appendix E) and interview protocol with a specific questioning route was prepared by the researcher (Appendix F). Interviews were conducted at individual sites to allow for minimal travel for participants and will be thirty and forty-five minutes in length. The researcher participated in note-taking during the focus group interviews to collect the data, in addition to tape recording the interviews.

\section{Data Analysis}

Both quantitative and qualitative data was collected and available for analysis in the present study. For the quantitative data portion of this study, the data collected from the closed-ended questions about the elements of mentoring program delivery and accountability present in the selected districts was analyzed and displayed in various charts, graphs, and tables. For the qualitative data in this study, detailed notes and jottings were collected and analyzed by the researcher. Merriam (2009) also suggested 
"verbatim transcription of recorded interviews provides the best database for analysis" which the researcher plans to utilize (p. 110). From the transcriptions, the researcher coded the data throughout the process and identified common threads and emerging themes across districts participating in the study. It was critical to "extend analysis to developing categories, themes, or other taxonomic classes that interpret the meaning of the data" (Merriam, 2009, p. 193) and move towards findings which provide support for the research questions guiding the study. Additionally, Emerson, Fritz, and Shaw (2011) reminded researchers to open code "... without regard for how or whether ideas and categories will ultimately be used, whether other relevant observations have been made, or how they will fit together" (p. 175). During data analysis, the researcher also reviewed the existing documents to gain key insights into the mentoring programs in addition to the surveys and interviews.

\section{Limitations}

There were several limitations of this research study but the most significant dealt with the accessibility to the participants desired for the study. During the process of designing the study, the researcher selected three school districts based on the proximity and similar size to her own district of employment. This created a limited scope and makes it difficult to generalize the findings to all school settings within the region. Within District A, there was also a potential hidden and unspoken benefit in regards to the researcher's use of participants within their own organization according to Drake and Heath's (2001) concerns about “insider research." Another limitation related to the survey instrument of the study, since the survey tool's reliability and validity have not been previously tested. A final, yet important limitation of the study, was the 
researcher's overall bias toward the topic of mentoring in education and its importance in supporting new teachers.

\section{Assumptions}

Prior to the beginning of the study, the researcher established connections with districts surrounding District A through coaching activities and other professional development opportunities. The researcher assumed districts in the area have discussed mentoring in collaborative settings since the district leaders meet and collaborate with each other on a variety of topics before making changes to district components. The researcher also assumed there would be a sample of mentor teachers available during the data collection phase to contact for participation in the study even though the number of beginning teachers varies from year to year.

\section{Significance of the Study}

This study aimed to provide further understanding on how mentor teachers receive training and are monitored throughout their mentoring in participating districts in the Southwest region of Missouri. The New Teacher Center policy report (2012) showed several areas of strength in regards to the Missouri standards for mentoring. In the same report, states were encouraged to evaluate existing program elements and study exemplar examples with the goal of informing practices and making shifts to strengthen mentoring programs. With a current gap in research in the United States on training and supports provided for mentors, this study could add an additional perspective from mentor teachers themselves in one region of Missouri.

The goal of the study was to gain information on current mentoring programs within select districts in the southwest region of Missouri. The researcher analyzed 
survey and focus group interview data collected from both leaders of mentoring programs and mentor teachers. Areas of strength in programming were identified which could result in duplication by other districts. Areas identified as opportunities for improvement could be discussed to improve mentor programs. Research has shown the amount of supports provided by districts and administrators for mentor training programs affects the mentoring experience, therefore, this study aimed to collect and analyze data about the mentor programming supports present in three Southwest Missouri districts.

\section{Summary}

Since the growth of mentoring programs in the 1990s, an increase of varied mentoring activities has occurred across the United States. In 2012, a state-by-state analysis of mentoring programs by The New Teacher Center found only three states were

meeting the majority of the review's ten mentoring criteria. More specifically, the review of Missouri's mentoring programs highlighted several notable areas of strength in mentor program elements and areas in which Missouri is not currently an exemplar example. The areas needing further consideration in Missouri include program delivery, funding, and program accountability. For this reason, this research plans to utilize a convergent parallel mixed methods to study the elements of program delivery and accountability in mentoring programs in select districts in the southwest region of Missouri. Mentor program leaders and mentor teachers in three Southwest Missouri school districts were the primary focus for data collection. 
SECTION TWO:

ORGANIZATIONAL AND LEADERSHIP CONTEXT FOR STUDY 


\section{Introduction}

When mentoring is a priority, "there is no better form of professional development for teachers than a thoughtfully designed and carefully implemented mentoring program" (Ganser, p. 16). Across the United States, changes in mentoring policies in the past decade have impacted the design and implementation of mentoring programs, however, the outcomes of mentoring programs are still similar to the description from a 1996 report by the National Foundation for the Improvement of Education:

For school administrators, mentoring aids recruitment and retention; for higher education institutions, it helps to ensure a smooth transition from campus to classroom; for teacher associations, it represents a new way to serve members and guarantee instructional quality; for teachers, it can represent the difference between success and failure; and for parents and students, it means better teaching. (p. 16)

In more recent years, multiple organizations and state policies have focused efforts on mentoring in the United States as a whole. One of these organizations, The New Teacher Center (NTC), has provided reports and resources applicable to states interested in studying mentoring programs. Additional organizations such as the National Commission on Teaching and America's Future (NCTAF) and Association for Supervision and Curriculum (ASCD) have both been advocates for mentoring for over a decade as well. Furthermore, the Missouri Department of Elementary and Secondary Education plays a critical role in understanding organizational aspects related to this study's focus in Southwest Missouri. 


\section{Organizations Focused on Mentoring}

Since its establishment in 1988, The New Teacher has been a national non-profit organization originally based at the University of California-Santa Cruz. The mission of the organization is to research, design, and advocate for high-quality induction programs while serving as a resource for policymakers and educational leaders interested in mentoring programs (The New Teacher Center, 2016). The New Teacher Center has been actively involved in shaping legislation, rules, regulations, and standards in regards to induction programs at the federal, state, and local levels. Additionally, The New Teacher Center's policy informed the Every Student Succeeds Act and produced State Policy Reviews, which have both impacted education in recent years.

Another advocate of mentoring in education, The National Commission on Teaching and America's Future (NCTAF), was founded in 1994 by the Teachers College of Columbia University. The focus of NCTAF was to bring policymakers and practitioners together to research the difficulties in recruiting, developing, and retaining teachers. Similarly, the Association for Supervision and Curriculum (ASCD), founded in 1943, is a leader in developing programs, products, and services related to professional development, capacity building, and educational leadership. ASCD is comprised of a diverse group of members focused on how educators learn, teach, and lead and how each learner can succeed.

\section{Missouri Department of Elementary and Secondary Education (DESE)}

An understanding of mentor programs across the states is helpful in gaining insights about the variances in mentor programs in the United States. Additionally, a deeper understanding of Missouri's mentor program standards is critical in exploring how 
districts in Missouri are meeting the standards. In the state of Missouri, mentor program standards were updated in 2008 when the Missouri Board of Education established standards for effective mentoring programs. These standards specified mentor programs should include the following: an introduction to the cultural environment, a systematic and ongoing program review/evaluation, an individualized plan for beginning educators aligned with the district's goals and needs, appropriate criteria for selecting mentors, comprehensive mentor training, a complete list of responsibilities for beginning teacher and administrators, sufficient time for mentors to observe beginning educators and for the beginning educators to observe master educators (DESE, 2015).

\section{Organizational Analysis}

Leaders need to be knowledgeable about the mentoring needs in their organizational setting. Collaboration about mentoring standards and district goals for mentoring should include communication and input from a variety of stakeholders. Administrators, school board members, partnering universities, teachers in leadership roles, and program directors should communicate about mentoring to ensure a commitment to providing mentor supports for teachers as a common goal. If a district aims to increase job satisfaction and decrease turnover while providing motivation and feedback, mentoring may provide an avenue for supporting these goals.

\section{Mentoring through a Structural Lens}

Bolman and Deal (2008) emphasize the structuring of roles and responsibility in order to place people in positions to help accomplish organizational goals. Additionally, Bolman and Deal (2008) recognize, “Organizations divide work by creating a variety of specialized roles, function, and units" (p. 68). Research by Gold in 1996 indicated 
structured mentoring programs play a role in supporting the transition from teacher preparation to classroom environments. In a study by Grossman and Davis (2012) effective mentoring was found to include three features, "highly trained mentors, a focus on content, and allocated time for mentoring” (p. 55). Similarly, Jones and Pauley explored the critical elements for implementing mentoring to include an introduction to mentoring, support for engaging in the mentoring process, and communication aspects of mentoring experiences. The role of providing trained mentors to support the mentee during the transitional years is typically assigned to a mentor program leader or director. The focus for the mentor and allocations of time are often driven by state and district decisions.

Further, the Missouri Board of Education rules and standards for mentor programs across the state provide a benchmark to "...maintain a specified level of quality" (Bolman \& Deal, p. 55). Likewise, Ganser (2005) noted “...without program goals laying out expectations for mentoring directly related to effective instruction, mentors tended to construct a definition of mentoring that was largely personal in nature and limited in scope" (p. 7). It is critical for each district leader to coordinate the expectations of their district to match the level expected by state standards for mentoring programs. This could be accomplished through district level meetings, district planning groups, networking with other districts, or a mix of options. Once mentor program elements have been established, the district leader can then identify mentor teachers who exhibit levels of expertise or specialization to help perform the supports of the mentoring program. Following the selection of mentor teachers, the leader can then group mentors with 
mentees based on positions, schedules, goals or desired outcomes, or a variety of aspects to hopefully yield the most effective pairing.

With a growing need for mentor teachers to mentor the increasing number of new teachers in the profession, it is increasingly important to consider the goals and standards for which Missouri induction programs are aimed to accomplish. Bolman and Deal (2008) also cautioned if structure is overlooked, the energy and resources used within the organization might not be effectively coordinated. Kalin et al. (2010) has described mentoring programs as both closed and open systems that are complex and unstable, therefore, creating a complex thinking system of mentoring. This complexity has guided The New Teacher Center's model for mentoring to suggest "careful one-on-one mentoring by explicitly trained veteran teachers with strictly limited caseloads."

Overall, mentoring programs across the United States vary in design, organization, implementation, and evaluation methods. Mentor programs can vary due to population, partnerships with universities, and policies or mandates which are enforced. Portner (2005) indicated, “Adequate mentoring programs more or less meet modest goals and are supported by minimum resources, but they neither operate systematically nor embody other elements that are essential to the ongoing success of mentoring programs" (p. 2). Furthermore, Portner noted states or districts do not typically assess their mentoring programs, which means reflection on how to modify or improve the programs is unlikely. For this reason, mentoring supports in a district may need to include additional resources and energy to accomplish the greater goals of professional development and retention of new teachers in addition to mentoring. 


\section{Mentoring through a Human Resource Lens}

"The human resource frame centers on what organizations and people do to and for one another" (Bolman \& Deal, 2005, p. 117). The role of mentoring provides an opportunity for a mentor to provide supports for each mentee they may serve. The role of mentoring aligns with multiple human resource principles. The principle of keeping employees by promoting from within and sharing the wealth aligns with the goals for training mentor teachers. Mentor teachers are selected based on knowledge and skills they can share within the educational setting with new teachers. Mentors can collaborate and share data with mentees in order to support each other and aid in the retention of new teachers.

Additionally, mentors invest in creating learning opportunities for the new teacher. The goal would be for quality interactions which provide job-embedded professional development. Interactions between the mentor and mentee could be critical opportunities for sharing strategies and information to help with each mentees' individual needs. The relationship which develops between the mentor and mentee could stretch beyond the initial years of mentoring and develop into mutual supports for one another. Bolman and Deal (2005) noted, "When individuals find satisfaction and meaning in work, the organization profits from effective use of their talent and energy" (p. 164). Studies on mentoring have indicated induction supports for beginning teachers should also be a school-wide and collective effort, not solely the responsibility of the mentor. Additionally, The New Teacher Center suggests mentoring should support new teachers into their second and third years in the profession to allow time for deeper learning to 
occur. This type of multi-year mentoring is suggested in several state mentoring program descriptions.

\section{Mentoring through a Political Lens}

Several aspects of the political frame, such as the allocation of scarce resources, directly relate to mentoring. Time and money are both key components in selecting and providing training and compensation for mentor teachers. Sweeny (2005) outlined the importance of providing sufficient time for mentors to learn mentoring strategies and for using their mentoring time most effectively. Without sufficient time for training and interactions with their mentees, Sweeny (2005) argued people will struggle and show little to no improvement. Additionally, mentoring could be viewed as unrealistic or as an inadequate support without the sufficient resources and time (Sweeny, 2005). Similarly, The New Teacher Center (2016) noted, "Dedicated state funding is needed to establish new educator support as a state interest and priority."

While local control of schools has become a priority for many districts, there are benefits to having new teacher induction programs as a focus of state policy and leadership. "State-led induction program standards, program tools and infrastructure can provide flexibility to local school systems to design and develop support systems for beginning educators that fit their context without sacrificing excellence in program design" (NTC, 2016). State-led programs can offer both guidance and support for mentoring programs as well as developing expectations to provide every beginning teacher with mentoring support. Furthermore, "policy matters because it heavily influences the provision, design and scope of induction and mentoring for new educators" (NTC, 2016). 


\section{Leadership Analysis}

Feiman-Nemser (1993) discussed mentoring as a strategy of reform which must include the aspects of strong instruction, an understanding of how teachers learn, and a support which occurs in a culture of collaboration and inquiry. Furthermore, Daloz (1999) described the leadership role of mentoring as needing three aspects to best meet the need for providing learning-focused relationships. These three functions are (a) offering support, (b) creating challenge, and (c) facilitating a professional vision. The first function of offering support can include emotional, physical, instructional, or institutional support. The aspect of providing support must also be balanced with providing challenges which promote cognitive dissonance and opportunities to plan, problem solve, and reflect. The final function mentor teachers must balance when supporting new teachers focuses on expectations, values, and beliefs. An understanding of these functions coupled with connections to servant leaders and the component of communication all frame the leadership analysis for this section.

\section{Mentors as Servant Leaders}

Servant leadership, which is focused on serving first with regards to the benefits and growth of others, connects closely to Daloz's mentoring supports. Both the characteristics of listening and commitment to the growth of people strongly align with mentoring. Listening as defined by Spears (2010) is an "interactive process that includes sending and receiving of messages." Servant leaders demonstrate the importance of being receptive of what followers have to say and acknowledging others' viewpoints. In addition to listening, servant leader's commitment to the growth of people helps them guide personal and professional growth in their followers. This commitment could 
include “...opportunities for career development, helping them develop new work skills, taking a personal interest in their ideas, and involving them in decision making” (Spears, 2002). Several of these overlap with personal qualities identified by Vonk (1993) as unique to mentor teachers which include open-mindedness, reflectiveness, flexibility, listening skills, and a helping attitude.

Additional characteristics of servant leadership originally included empathy, healing, awareness, persuasion, conceptualization, foresight, stewardship, and building community (Spears, 2002). Over time, other key characteristics of servant leadership have been identified which also align with mentoring. These include developing people, inspiring and influencing others, wisdom, and trust. Servant leadership emphasizes leaders be attentive to the concerns of their followers, empathize with them, and nurture them (Northouse, 2013). Additionally, servant leadership provides leaders with the opportunity to empower others and serve the greater community or organization. Northouse (2013) noted servant leadership behaviors could potentially impact the follower's performance and growth. If followers realize their capabilities from the nurturing they received, then Northouse (2013) recognizes self-actualization as an expected outcome.

\section{Communication}

Both the servant leadership characteristic of listening and the leadership aspect of communication play a role in mentor and mentee relationships. Levi (2014) stated, "Communication is the process by which a person or group sends some type of information to another person or group" (p. 103). One of the characteristics of the sender that directly applies to mentoring is the credibility. Levi (2013) noted credibility relates 
to expertise and trustworthiness and the receiver of the message must believe the sender possesses the expertise in order to be receptive of the message. The receivers also have characteristics which impact communication including intelligence, language skills, and self-esteem. Research has shown mentors often discover transferring knowledge to adult learners such as their mentees is different than transferring to students. For these reasons, it could be critical for messages to be tailored so communication can begin to flow between a mentor and mentee.

Furthermore, studies by Feiman-Nemser (2001) have shown strong relationships between beginning teachers and their mentors are essential to success. Feiman-Nemser (2012) stated when mentors act as "cothinkers and coplanners," they can help beginning teachers to "reframe challenges, design and modify instruction and assessments, and analyze and promote student learning” (p.13). Similarly, Lipton and Wellman (2005) highlighted a need for mentors and mentees to communicate shared goals and mutual needs throughout their interactions together. Additionally, Bieler (2012) indicated common themes desirable of the mentor-mentee partnership, which included opportunities for observation and reflection as well as reciprocal relationships. Research by Danielson (1999) found reflective activities and professional conversations between mentors and mentees helped new teachers tackle the challenges of teaching.

\section{Organizational Backgrounds for the Present Study}

The setting for this particular study was derived from both The New Teacher Center's review of Missouri's mentoring supports and the standards for mentoring as set by The Missouri Board of Education in 2008. Within the state of Missouri, districts have been selected to explore current mentor program delivery and monitoring including three 
public school settings within a close radius. Each of the districts have a current mentoring program in place which can be traced back further than the desired research range of this study.

\section{District A}

"Student dedicated every day, student driven in every way"- this is the current mission of District A in Southwest Missouri. With a total of four elementary schools, a middle school, one junior high school, one high school, an alternative school, and an early childhood program, District A's enrollment during the 2015-2016 school year is around 5,800 students. At the district office level, leadership positions include the superintendent, associate superintendent, chief financial officer, director of communications, director of operations, director of special services, director of secondary learning, and director of Federal Programs. As of 2016, leadership at the building level included sixteen administrators.

Additional features of District A include the use of Professional Learning Communities, Positive Behavior Intervention Supports (PBIS), and the inclusion of coaching and mentoring supports. In recent years, the mentoring program for District A has been adapted and changed based on updated requirements from DESE and a new director leading the program, as indicated by district mentoring documents. A 2015 Professional Development Plan indicated objective six includes the aspect of supporting new teachers through the use of mentoring and the review of mentor assignments.

\section{District B}

With a total of five elementary schools, a middle school, one junior high school, one high school, and an Early Childhood Center, District B serves approximately 4,700 
students. The district's mission is to prepare each student for a success future and the vision includes being a leader in academic success while being dedicated to community priories. At the district leadership level, District B includes the positions of superintendent, assistant superintendent of academic services, and executive director of operations. Additional features of the district includes Positive Behavior Intervention Supports (PBIS), Partnership in Comprehensive Literacy, and STEM classes in addition to a new teacher mentor role for the district.

\section{District C}

Since the early 1960 's, consolidation of districts created District C which is also located in Southwest Missouri. With five buildings and around 2, 200 students in 2015, District $\mathrm{C}$ is considerably smaller than the other two districts in the study. The district's mission is to "Provide all students with the skills and knowledge necessary for successful participation in our changing society." District leadership positions in District C include building administrative positions, the superintendent, and an assistant superintendent position. The district has a visible profession development goal which includes efforts to support beginning teachers though the use of mentoring as well as providing professional learning communities for all teachers.

\section{Implications for Research in Context}

The present study will aim to apply an understanding of organizational and leadership contexts of mentoring while examining elements of mentoring programs across three districts in Southwest Missouri. Each of the districts have structural components of mentoring identified in mentoring documents, however further research is needed to explore the components of training and accountability from a structural 
standpoint. This research also hopes to gain insight on the human resource components of job-embedded professional development and relationships between the mentor and mentee at each of the district sites. Although the policy and political aspects are critical in understanding mentor programs, the funding and Missouri policy part of this study will not be a main focus. Through surveys and interviews with teachers in mentoring roles, connections to the servant leadership characteristics could emerge from responses.

\section{Summary}

With numerous organizations advocating for a focus and support for induction programs, mentoring continues to be spotlighted as an avenue for supporting beginning teachers. NTC, NCTAF, and ASCD all study and report on topics regarding mentoring, mostly on a national scale, while DESE impacts mentoring aspects directly in the state of Missouri. Each of these organizations highlights key organizational elements necessary for mentor programs. The elements of program goals, collaborative relationships, and the funding and allocation of time are all critical discussions regarding mentoring. In addition, connections to servant leadership and the aspects of listening and growing others has important implications for understanding mentoring from a leadership lens. All of these organizational and leadership aspects will provide understanding to further aid in the study of the three selected school districts. 
SECTION THREE:

SCHOLARLY REVIEW 


\section{Introduction}

The topic of new teacher mentoring or teacher induction has been an on-going conversation in education and research since the late 1900s (Strong, 2009). Even with the growth of mentoring programs in the 1960s and 1970s, a mere seven states had formal mentoring programs in place in 1996. Further, even though a primary goal of employing an increased number of mentor programs in the United States has been to help with new teacher retention, $30 \%$ of new teachers were reported as leaving the profession within three years and an upwards of 50\% leaving within five years according to DarlingHammond (1997). According to The New Teacher Center (2012), it was not until 2002 when the number of states with mentoring programs had dramatically increased to 33 and possible gains of new teacher retention were specifically highlighted in studies.

Numerous studies conducted by Ingersoll and Kralik prior to 2004 led to the identification of varying levels of induction support which new teachers often received. A basic induction level of support was characterized by providing beginning teachers with support from both a mentor and administrator(s). When additional supports such as new teacher seminars, common planning, or collaboration with others occurred, the support was further classified as basic induction plus collaboration. A third level of support included the new teacher's inclusion in a teacher network which was classified as a basic induction plus collaboration plus teacher network plus extra resources level (Ingersoll \& Kralik, 2004). Surprisingly, Ingersoll and Kralik (2004) found only 1\% of new teachers received the third level and $3 \%$ of new teachers did not receive mentor or induction supports at all. Varying levels of supports and stages in development continue 
to spotlight the need to examine and understand the complexity of mentoring as an induction support.

Furthermore, research has shown the importance for beginning teachers to receive intense and systematic mentoring during the first year, with a focus on becoming effective educators rather than solely focusing on survival (Darling-Hammond, 2003). Additionally, Hughes (2006) noted "Mentor teacher programs continue to gain support as vehicles for promoting the development and retention of quality beginning teachers." During a report by the National Commission on Teaching and America's Future (1996), findings showed several districts in various states have reduced attrition rates of beginning teachers by more than two-thirds by providing expert mentors with release time to mentor new teachers at the start of their careers. Furthermore, evidence has shown higher job satisfaction and commitment in addition to retention when effective mentoring occurs as a support for beginning teachers (Feiman-Nemser, 2012).

The ATE National Commission on Professional Development and Support of Notice Teachers has identified six dimensions of quality mentoring programs (Odell, 2006). Two of these six dimensions directly relate to the current study which include mentor teacher preparation and development as well as program administration, implementation, and evaluation. The additional four dimension include program purpose and rationale, mentor selection and mentor/novice matching, mentor roles and practices, and school, district, and university cultures and responsibilities. These six dimensions align with the criterion which The New Teacher Center used to review state mentor programs. 
The review of literature for this study is organized beginning with an examination of The New Teacher Center's study of state-by-state mentoring supports. Additional mentoring studies from across the states and countries were also examined throughout the literature review. Further, the examination of studies indicated common issues of mentoring which informed this review, along with a focus on the training and monitoring of mentor teachers. The inclusion of previous studies focused on training and monitoring helped narrowed the scope of the review to best align with the research questions of the present study.

\section{The New Teacher Center Study}

With an increasing number of states and countries starting to require induction or mentoring programs to aid in supporting the needs of beginning teachers (New Teacher Center, 2012), numerous studies have emerged on mentoring programs in recent years. Between 2010 and 2011, a sizable study by the New Teacher Center (2012) included a review of induction and mentoring programs across all fifty states. The study sample of 316,000 United States educators found between seven and thirty percent of beginning teachers reported they did not receive formal mentoring support, even in states with mentoring requirements in place (New Teacher Center, 2012). Additionally, first and second year teachers in the study indicated even when mentors were assigned, the supports of planning, observations, and student data analysis were not part of the mentoring received by the new teachers. For states requiring mentoring programs, this type of data is a reminder that simply mandating the programming will not guarantee effective mentoring outcomes. 
Furthermore, The New Teacher Center's (2012) review of state policies reported 15 states require both mentor training and professional development. More specifically, some states offer training which includes elements such as knowledge of state teaching standards, formative assessment, classroom observation, reflective conversations, and an understanding of adult learning theory, while other states rely on local programs to provide the mentor training (New Teacher Center, 2012). Additionally, the recent policy review by The New Teacher Center's (2012) found 22 states were participating in some aspect of reviewing mentoring programming. The states currently use surveys, audits, site visits, or evaluation data as possible methods for assessing accountability. The review also found only three states currently utilized multiple accountability measures, while an additional five states "create the tightest linkage between program evaluation and the state's induction program standards" according to The New Teacher Center (2012, p. 30).

A further look at the state-by-state analysis at each of the criterion highlights key findings and recommendations for mentor programs. The first criterion considers whether all teachers are served by induction supports during their first two years in the profession. The study found six states require more than the two years of support, five states (including Missouri) require two years, 13 states require one year, and three states require support without a timeframe. State policies and funding were both indicated as factors which effect the number of years for induction supports across the states (NTC, 2012). Similarly, the second criterion is focused on serving administrators with two years of induction support. Goldrick et al. (2012) noted, "In the life of a new teacher, the school principal can be a key facilitator or inhibitor of their professional trajectory" (p. 4). 
Therefore, it is critical to provide similar job-embedded supports through coaching and mentoring for administrators. Further, Goldrick et al. (2012) found "...school and district administrators need an opportunity to build leadership capacity while creating school conditions that support teacher development and student learning" (p. 4). While the study found states were less likely to provide administrative induction supports (17 states with varying degrees of support), Missouri was one of three states which requires two years of induction support for administrators.

The New Teacher Center's study (2012) of the formal standards for design and operations of induction programs is the focus of criteria three. In response to some states informal guidance for standards, Goldrick et al. (2012) noted “...program standards are preferable because they are written as criteria and lend themselves to the development of other state infrastructure components in support of program development and improvement- as opposed to serving solely as a compliance-driven mechanism" (p. 7). While 15 states had formal standards for mentor programs, another 20 had more informal plans for mentor programs. The findings of the 2012 NTC study suggest states either adopt formal standards or review the current informal standards.

Further analysis of state-by-state induction supports focus on mentor quality with criterion 4-6, specifically mentor selection, mentor training, and mentor assignments and caseloads. The study found more than half of the states have guidelines in place for mentor selection and training, however, fewer than half have guidelines for mentor assignments and caseloads. The New Teacher Center (2012) induction model addressed specific guidelines for mentor training such as 24 full days of mentor professional development in the first two years and mentor forums. Goldrick et al. (2012) noted 
"While such intensive mentor professional development may not be warranted as a state requirement, mandating some on-going support to deepen and develop mentor knowledge is key" (p. 10). Further, NTC found full-time mentor assignments as the most flexible means for providing support to new teachers and noted:

It allows mentors to focus exclusively on their critical role in supporting beginning educators. In addition to freeing mentor teachers from balancing mentoring duties with full (or reduced) teaching load, employing fewer full-time mentors allows induction programs to be more selective and choose the highest quality candidates for this important role. (p. 12)

The New Teacher Center (2012) study continued with a focused look at the program delivery components of contact time, classroom observations, and formative assessment. While nine states address all three of these components, NTC (2012) made specific recommendations for making improvements for program delivery. For contact time, NTC (2012) recommended “...creating robust requirements for mentor performance and program standards that explicitly require sufficient time and for mentormentee interactions" (p. 21). This could also include dedicated time or a specific quantity of time for mentors to provide support for mentees. The New Teacher Center (2102) also recommended a required formative assessment system which would include classroom observations to guide the interactions between the mentors and mentees. The goal would be “... accelerating beginning teacher development and customizing feedback and support" (p. 21). In addition to these recommendations, NTC (2012) encouraged the consideration of full-time release mentors, which is discussed in several of the criteria. 
Three final criteria were focused on in The New Teacher Center's study of induction, including funding and the accountability of both educators and induction programs. The findings regarding funding across the states found only 11 states provided funding for all of the school districts within the state. Additionally, the study noted six states dedicated all of the funding to providing mentor stipends rather than saving funds for programming. NTC (2012) recommendations included using funds for programming in addition to stipends and considering grants or matching local funds to support mentor programming. Further, NTC (2012) noted, "Funding legitimizes the state's central role in accelerating new teacher effectiveness by regulating and supporting the quality of local induction programs- and recognizes the real costs associated with comprehensive, highquality induction programs" (p. 22).

Goldrick et al. (2012) discussed the need for criterion nine which focuses on educator accountability and noted, "When induction is comprehensive, required as a condition of licensure, and the successful completion of a performance assessment is required at the end of the induction period, states have the opportunity to develop a truly performance-based system of licensure" (p. 26). The New Teacher Center (2012) found 22 states required some level of participation in an induction program as a requirement for advancing licensure. Similarly, 22 states were found to meet the requirements for criterion ten as well. Alaska, California, and West Virginia were noted as three of the strongest examples of program accountability. Alaska was noted for the academic research component of programming, California for statewide accreditation system which includes induction, and West Virginia for including audits of program implementation. However, Goldrich et al. (2012) concluded, "No single U. S. state has perfected its 
induction policy to ensure the provision of high-impact, multi-year induction support for all beginning educators, and half the states still don't require all beginning educators to receive induction or mentoring support" (p. 32).

\section{Mentoring Across the States and Countries}

As mentor programs continue to increase across the United States, it is not surprising studies are emerging which include a focus on state specific mentor programs. In 2002, a study in Virginia focused on the implementation of mentor programs was explored on a state-wide basis. After mentoring was legislated by the Commonwealth in 1999, beginning teachers started being assigned a mentor teacher who met specific qualifications and who had received required training. The required training in Virginia for mentors focused on four areas, which included the aspects of formative assessment, developing personal professional development plans, providing individualized assistance, and performance standards and evaluations (Hughes, 2006). Since the districts were designing and implementing mentor programs and these four areas were required, the study set out to specifically explore what training the mentors were receiving.

The study by Hughes (2006) included both a survey and interview component. While the surveys were intended to collect general information from a large number of districts, the interviews were conducted to provide insight on the design and implementation aspects in a smaller subset of districts. The survey questions were focused on program goals, design features, mentor selection and training, and program evaluation and the survey rate of completion was $90 \%$ for the study. Additionally, the interview questions provided insight on the design and implementation of mentor programs through a series of twenty interview questions and spanned across six districts. 
The results of the study in Virginia found 70 percent of the surveyed areas provided mentor training prior to mentoring (Hughes, 2002). The remaining mentors received training, which was found to be diverse, after mentoring had started. The themes which emerged from the study in Virginia indicated mentors learned what new teachers need, but not how adults learn or how to best teach adult learners. Additionally, the study found selecting and training quality mentors were ranked as two of the top three difficulties in the area. Beyond the selection and training of mentors, the state-wide study also found concerns with consistency and quality interactions between mentors and beginning teachers. One of the study's implications was training mentors requires thought, time, and money, which should be considered when implementing a mentoring program in any state or district. Hughes (2002) also found three out of every ten mentor teachers were lacking training or formal instruction about their roles across the study area. Additionally, teachers indicated training was not aligned to their mentoring needs, and the results noted time and money were needed to improve the training supports provided.

Another mentoring study in the Illinois area focused on a four-year examination of 39 sites. In addition to the findings from the surveys and interviews, the study of sites across Illinois included examination of written items related to mentor programming. This included workshop materials, program descriptions, and evaluations or data collected as evidence of the mentoring which occurred. The overall goal of the mixedmethod design was to collect both the inputs of induction and the various outcomes. The study found vast variations in the different supports available and activities for both the mentor and mentee. 
One major finding concluded more than half of new teachers in the sites did not receive the 1.5 hours or more of weekly mentoring support as required by the program. Furthermore, the 2008 Illinois Induction Program Standards addressed numerous aspects of mentoring which were related to training and monitoring of mentor teachers across the sites. The findings concluded $56 \%$ of the mentors were involved in on-going support to some degree, $35 \%$ were supported monthly, and $10 \%$ did not receive on-going support. The study also found:

Programs that have more control over their mentors- those that have more stringent requirements for mentor selection, provide more training and on-going support, and hold mentors accountable for their mentoring- provide more intense mentoring and a strong focus on instruction, two contributors to positive teacher outcomes. This finding suggest that programs can improve their induction support by focusing on the mentors. (p. ii)

Additionally, the study found $35 \%$ of the mentors completed logs to document interactions with their mentees on a monthly basis and $28 \%$ completed written summaries at least monthly to document meetings with mentees.

In a comparative analysis of mentoring of two U.S. programs, Feiman-Nemser and Parker (1992) noted "...the contexts of mentoring shape the perspectives and practices of mentors" (p. 14). The study found the work conditions, preparation, and social structures of mentoring all created various types of supports for new teachers in the Los Angeles and Albuquerque locations. Further, the study noted three perspectives on mentoring, including mentors as local guides, mentors as educational companions, and mentors as agents of cultural change. The study found Los Angeles mentors to identify 
as local guides with limited time to support issues beyond immediate problem solving and advice. In Albuquerque, mentor teachers were identified as educational companions who were able to provide professional supports beyond problem solving and advice. Feiman-Nemser and Parker (1992) noted "...beginning teachers will come to value collegial exchange if they and their mentors regularly experience the power of observation and conversation as tools for improving practice” (p. 15).

Beyond induction programs in the United States, research on the approaches of mentor programming in other countries can offer relevant approaches for discussing and improving supports across the states. In a study by Wong, Britton, and Ganser (2005), five countries were examined to report the systematic approaches the countries have employed to support effective mentoring. The countries included in the study were Switzerland, Japan, France, New Zealand, and China, all of which have well-funded mentoring support for a minimum of two years for all beginning teachers. Wong, Britton, and Ganser (2005) provided international findings of the mentoring practices in each country.

In Switzerland, Wong, Britton, and Ganser (2005) noted the model of induction assumes new teachers need mentors and works to include induction supports beginning during student teaching. Beginning teachers in Switzerland receiving induction supports participate in practice groups, counseling, courses, and self-evaluations. Each of these supports is led by a team of induction leaders who receive both leave time and pay for the leadership role. Much of the focus in Switzerland as documented by Wong, Britton, and Ganser focused on lifelong learning and the development of both the person and professional. 
Similarly, Wong, Britton, and Ganser (2005) noted the goal for personal learning and development of new teachers in China. An additional focus for new teachers is inclusion into the culture of joint work. Some of the induction supports documented included welcome ceremonies, workshops and courses, hot line call supports, mentoring awards, training sessions, peer observations, various lesson supports, research and project opportunities, and celebrations for collaboration. Additionally, lesson-preparation groups, teaching-research groups, and teaching competitions guided the mentor supports documented in the study. Similarly, a variety of supports for new teachers are provided in Japan which include a focus on observations by guiding teachers. These observations include public lessons and peer observations, and new teachers also are required to complete action research. The support which begins for new teachers in Japan, however, is only the first phase of learning, and program supports continue up to 20 years after induction supports begin.

In contrast from Switzerland, China, and Japan, Wong, Britton, and Ganser (2005) included New Zealand in the study as a similar example to the single mentor model provided in the United States. The researchers noted while the five countries offer differing supports, the commonality of highly structured programs which are rigorous and monitored is worthy of consideration for improving United States mentoring programs. Further, Wong, Britton, and Ganser (2005) noted in more than 30 states in the U.S., “...one-on-one mentoring is the dominant or even the sole strategy for supporting new teachers and it often lacks real structure and relies on the willingness of the veteran teacher and the new teacher to seek each other out" (p. 383). This is in contrast to the 
phases of professional development which include collaborative group work and research components in the countries focused on in the study.

In a separate study of an Australian mentoring preparation program, 17 mentor teachers who participated in a Mentoring Beginning Teachers program were studied through qualitative measures. Following key recommendations at the state level, highly skilled mentors were suggested to assess and guide beginning teachers, so the Mentoring Beginning Teachers program was developed to provide mentoring supports that focused on the process of collaborative inquiry and critical reflection. Through focus groups and semi-structured interviews, the study aimed to identify the impact of both the program on mentoring practices and on the mentor teachers on a personal and professional level. Findings from the study showed the program "assisted in building a common language and shared understanding around the role of mentor, consolidated a collaborative inquiry approach to mentoring and provided opportunity for self-reflection and critique around mentoring approaches and practices" (Beutel, et al., 2017, p.170). Further understanding of the development and funding for the program were discussed as an increased effort to advocate for more formal mentoring in Australia.

\section{Issues in Mentoring}

A series of quantitative studies by Ingersoll and Kralik (2004) explored the common topic of mentoring as well as one of the commonly studied aspects of mentoring: teacher retention. Experimental designs of the studies found mentoring programs had a positive effect on the retention of new teachers, however, additional studies have since then argued no statistically significant link between mentoring and retention. Similarly, the issue of mentor program effectiveness is common among 
research on the topic of mentoring. Fideler and Haselkorn (1999) argued teachers were more effective based on how receptive they were during the early years of their career. Research since then is often varied and produces mixed results about the effectiveness of mentoring on new teachers.

In a review of nearly 170 empirical studies on mentoring, Hobson, Ashby, Malderez, and Tomlison (2009) discussed both benefits and disadvantages of mentoring. Findings from the study noted some limitations in translating the benefits directly related to the mentors to the benefits of mentoring as it relates to schools and systems. Hobson et al. noted both limited research and the complexity of researching mentoring limits the evidence for benefits beyond mentors and mentees. For example, Hobson et al. (2009) discussed it could be possible, "that both schools and educational systems may benefit from the enhanced retention of those teacher-mentors who become more confident and committed as a result of their participation in mentoring," however, this claim has limited evidence to support it. Further, Hobson et al. (2009) noted:

In the last 15 years or so a vast amount of research, across many countries employing mentoring as a means of supporting the professional learning and development of beginning teachers, has uncovered the existence of variation in the nature and quality of mentoring support provided and documented evidence of poor mentoring practice, which have negative consequences for the learning of mentees, and (thus) for the schools and educational systems into which they are being inducted. (p. 210)

The main findings Hobson et al. (2009) discussed as limitations and disadvantages of mentoring included unavailability of mentors for emotional and psychological support, 
missed opportunities for mentees to be challenged by mentors, and interactions which do not include pedagogical supports but rather technical or practical issues.

Additional limitations to current research on mentoring were noted by Waterman and He (2011) as they highlighted a need for "...multiple studies on the same mentoring program done by researchers from different paradigms using different research methodology" (p. 153). This could help provide insights for stakeholders working to understand what constitutes effective or quality mentor programs. Waterman and He (2011) called for further emphasis on research which collaborates across schools, districts, and states, similar to The New Teacher Center's reviews of mentoring across states. There is a need to share resources and studies on mentoring which focus on the process of supports, and studies which potentially highlight findings related to mentoring and teacher retention, a popular focus area of mentor research.

The National Center for Research on Teaching Learning (1993) produced a fiveyear study focused on important issues of mentoring programs. The findings concluded to create successful mentoring programs, mentoring must connect to a vision of good teaching and be informed by the ways in which learning occurs. Additionally, mentoring as a professional practice must include opportunities to learn how to mentor. Further, a study by Haggarty, Postlethwaite, Diment, and Ellins (2011), included fifteen newly qualified teachers and mentors who participated in semi-structured interviews to discover the supports provided during the induction process. The study stated staff members in the role of mentors were "unsure of their own role" and not included in levels of training provided to other induction positions. Consequently, the newly qualified teachers received generic programming and help with fitting into the school environment as well 
as support primarily focused on behavior management. Findings of the study indicated mentor supports were limited to supports related to behavior management rather than ideas focused on pedagogical issues.

An additional study by Ormond (2011) assessed a mentoring initiative for secondary math and science teachers receiving mentoring in Australia between 2009 and 2010. This study included eight mentors and 16 mentees, of which the mentor teachers had completed graduate degrees, an average of 27 years of teaching experience, and were considered expert teachers in the areas of math and science. During the mentoring relationship, the mentor expectations included one hour per week of contact through writing or talking to the mentees and stipends were provided for the mentor teachers fulfilling these roles. As part of Ormond's study (2011) both quantitative and qualitative data was compiled during two stages of research with the participants providing both oral and written responses. More specifically, the data was collected during a seven month period in the forms of tally sheets, workshop responses, focus groups, and questionnaires.

The results of Ormond's (2011) study identified three highly ranked conversational issues in mentoring, namely, effective teaching approaches and strategies, finding suitable resources, and making the teaching content relevant and interesting to students. Further, Ormond (2011) noted "particular forms of mentoring do not suit all people, all of the time" (p. 68). There are complex issues such as cultural aspects of the school which result in isolation, loneliness, and a lack of initiation for the mentees in addition to the previously stated highly ranked issues. Similarly, studies have also shown mentoring programs do not all produce successful results, therefore it is important for 
researchers to continue to gather evidence in an effort to identify effective practices of mentoring and mentor training (Resta, 2006).

\section{Training Mentor Teachers}

A case study by Athanases et al. (2008) revealed the critical need to develop new mentors for the role of mentoring. Athanases et al., (2008) indicated there is "an assumption that teaching younger students translates well into mentoring new teachers effectively." Additionally, Athanases et al., (2008) described both explicit and implicit curriculum supports necessary for training mentor teachers which included aspects such as materials, resources, artifacts, activities, as well as the environment, organizational structure, norms, and cultures of the mentor program.

Research by Ganser (2001) found the majority of new mentor training begins with an introduction to mentoring at the beginning of the school year and is then followed by minimal ongoing support. Unfortunately, the design and frequency of follow up trainings vary and can often taper off lacking implementation of an effective mentoring model. Similarly, Hall (2005) stated "The most critical weak links in ineffective mentoring programs are mentor training and support” (p. 217). Research by Lipton \& Wellman (2003) acknowledged effective mentoring can include models of coaching, which mentors could learn during training. More specifically “... accomplished mentors [may] shift as needed between consulting, collaborating, and coaching stances to develop their protégés capacities to reflect upon practice, generate ideas, and increase personal and professional self-awareness" (p.153). These three stances of consulting, collaborating, and coaching can be beneficial as a training component of mentors. 
A study by Huling and Resta (2007) found several components are critical to aspects of training and placements of mentors, including the importance of matching mentors to a mentee in the same field, allowing for common plan time as a means for mentor and mentee interactions, and ongoing training. The study also found administrative support and the use of stipends to be important components for supporting mentoring. Further research by Huling and Resta (2007) noted two aspects which effect the placement of mentors which coincided with Perez and Ciriza's (2005) research which found school leaders needing to pay careful attention to how mentors are selected. Huling and Resta (2005) specifically detailed two questions about the traits which would make a mentor useful to peers and how mentors can be distinguished from other supports for beginning teachers. Both the traits and abilities of mentors as well as the attention to selection and training of mentors are both causes for further research according to Perez and Ciriza (2005).

According to Crasborn et al. (2008), "Trained mentors have been found to differ from untrained mentors in their tendency to guide their mentees through self-discovery of knowledge about teacher." Further, Crasborn et al. (2008) noted the skills of guiding and assisting necessary for mentoring can be improved when mentors are allowed the opportunity to practice the skills in training. Studies have also shown training mentor teachers to provide constructive feedback, daily support with issues, and recognition and affirmations are all effective in building confidence in beginning teachers. Wong (2004) noted however, if mentoring is not properly established and mentors do not receive training, then the mentoring supports have limitations. 
Odell's (2006) work found to prepare mentor teachers, sessions prior to the start of their mentoring role were beneficial, but continuing these sessions as frequent training should also be included. The ongoing training, as suggest by Odell, would provide opportunities for mentors to:

explore topics such as studying their own teaching, communicating with novices, supporting and challenging novices as they are learning to teach, mentoring toward standards-based teaching, providing constructive feedback, developing strategies for mentoring, studying mentor roles and responsibilities, assessing instruction, working with novices as adult learners, and promoting mentoring program goals. (p.207)

In the same study by Odell (2006), leadership was also recognized as an important element of supporting mentoring programs. Leaders of mentoring programs were found to often be responsible for coordinating the program, supporting program goals, and providing training or professional development as a component of the mentor program. It was suggested that program leaders collect data to inform program decisions and evaluate the goals and development of the programs overtime. Another result of Odell's study (2006) noted implementation and delivery of mentor programs can be difficult due to time constraints.

Grossman (2012) found high-quality mentors need training and support on how to provide mentees with a variety of educational supports. Numerous research studies have shown common themes new teachers are seeking support with and what should be provided by the mentor teachers. Bieler (2012) noted these themes could include support with curriculum navigation, discipline supports, and collaborative grading. Scherer 
(2012) also indicated each teacher has a unique set of challenges and requires a good fit for support which should be part of the mentoring selection and training process.

Further discussion of training for mentor teachers by Waterman and $\mathrm{He}$ (2011) discussed models which went beyond initial orientation meetings and workshop approaches. Black et al. (2008) discussed the use of a "Critical Friends Protocol" and training for mentors through a university course as methods for training mentors. In a 2006 study by McNeil, the use of a trainer-of trainer model and utilization of the zone of proximal development were guiding training supports for preparing mentor teachers for their support role. Additionally, to support the observation and reflection role, the use of a cycle of action-reflection-new action model was found as a training method in McNeil’s (2006) work.

While Hobson et al. (2009) noted research evidence of the effects of mentor preparation is underdeveloped, the study discussed the need to go beyond training. More specifically, Bullough (2005) discussed strategies for developing mentor identities through seminars and group supports. According to Bullough (2005), the goal of the seminars would be "...helping to overcome mentor isolation, facilitating the development of a shared discourse of mentoring, and enhancing mentors' skills development through conversations about mentoring practice and pedagogy."

According to the National Commission on Teaching and America's Future (1996), "beginning teachers who are paired with a mentor are more likely to move beyond concerns about classroom management and concentrate on student learning..." (p. 218). However, research by Evertson and Smithey (2000) indicated working with a mentor is not the only key to supporting new teachers, but more specifically, a trained 
mentor can provide a higher level of skills and support for their mentees when following effective models of mentoring. Perez and Ciriza (2005) noted, "Training mentors to not only help new teachers and reduce turnover, but actually address core issues."

\section{Monitoring Mentor Teachers}

Ganser (2005) noted typical monitoring of mentor programs over the years has included items such as an end of the year survey to measure satisfaction. Ganser also noted beginning of the year and mid-year surveys were less likely to occur, which negated from the possible goal of program improvement along the way. Additionally, Ganser (2005) encouraged “...the lack of absolute proof that mentoring works should never dampen the spirit of educators who know the value of mentoring...”(p.14). Similarly, research by The New Teacher Center (2012) encouraged states to develop structures which could evaluate mentor programs focused on improvement and outcomes using multiple measures to show growth throughout the year.

Waterman and He noted an emphasis on monitoring and evaluating mentoring in research from the lens of studying a program rather than a process. Their research was focused on studying the complete range of induction supports, including more than just the assigned mentor. Colleagues, administrators, outside mentors such as friends and family, were believed to all have an impact on the quality of mentoring supports. In their

review of fourteen studies, Waterman and He (2011) found only three collected data from mentors. Further, Waterman and He (2011) noted:

Considering the interactive nature of the mentoring relationship and the potential impact of mentoring processes not only on novices, but also on mentors, studies that view mentoring in holistic contexts should be better able to provide useful 
ideas, such as how mentors and novices might respond to administrative support, and how mentors might function as job embedded professional developers who also may benefit from professional development. (p. 153)

The New Teacher Center (2011) noted key elements to monitor mentor program quality beginning with the first element of consideration: to ensure compliance with state laws, regulations, and policies. This includes the operation of programs and ensuring trained mentors are supporting new teachers. Secondly, accountability systems should be in place to determine whether districts are implementing programs which match state priorities, taking into consideration any obstacles preventing mentor programing. A third element of monitoring mentor programs according to The New Teacher Center is to allow for analysis of the program with a focus on improvements. NTC (2011) stated "When an accountability system allows for an honest analysis of program strengths and challenges, and enables opportunities for rich feedback and discussion, it provides a platform for enabling all programs throughout the state to improve" (p. 29). A fourth and final element suggested by NTC as part of the monitoring of mentor programs is to assess mentoring in the form of student and teacher outcomes. The goal would be to highlight how mentoring programs are providing effecting teacher and student learning and would assess teacher retention. Overall, NTC (2011) supports the monitoring of mentoring programs and noted, "State induction policies are most successful when they create an environment where local programs can thrive" (p. 29).

The New Teacher Center's review of state mentoring found under half of the states had exemplary measures for monitoring mentoring. The study did, however, identify Alaska, California, and West Virginia as strong examples of program evaluation 
and monitoring. NTC's study (2011) noted several possible options for monitoring mentoring which included:

...review of mentoring activities and time, administer new teacher or program surveys, conduct program audits or site visits, use program information for accreditation purposes, ensure programs adhere to state program standards, support induction program improvement, require programs to submit evaluation data. (p. 30)

Additionally, NTC (2011) noted some states which have developed a program continuum to provide a self-assessment option.

Furthermore, The New Teacher Center (2011) made recommendations for monitoring mentoring programs. One of the recommendations was to provide funding, which only two states currently do, for evaluation or accountability checks. The New Teacher Center also suggested annual surveys for all new teachers to gage the quality of mentoring support as well as site visits and interviews of mentor program leaders. Overall, the recommendations from the study (2011) focused on the need to, "Develop robust, thoughtful accountability structures that go deeper than compliance-oriented systems and move toward a focus on program improvement and the measurement of program outcomes" (p. 30).

Research by Hagger and McIntyre (2006) collected evidence from monitoring mentor teachers and learning from the mentor teachers' experiences. The study found mentor teachers were positively impacted both professionally and personally as a result of the mentoring role. The mentoring aspects which supported mentor teacher's development included self-reflection or critical reflection of practices, communication 
and opportunities to collaborate more with peers, and gaining ideas and perspectives from the mentees. In addition to these aspects, mentors reported increased confidence in their own practices and improved relationships with peers. Simpson et al. (2007) noted, "Effective mentors must also be willing and able to 'make their work public' and make explicit the factors underlying their classroom practices" (p. 212).

\section{Summary}

Since the continued growth of formal mentoring programs, research has increasingly shown the importance of mentoring programs as a means for supporting beginning teachers. The New Teacher Center (2012) conducted a state-by-state analysis which identified no one state has all of ten of the criteria for providing a comprehensive and multi-year induction program. The findings and recommendations of the NTC study from 2012, in addition to studies across the states and numerous countries have provided insights about mentor programs as well as common issues related to mentoring. For the purpose of this study, this scholarly review focused on mentoring studies which could further support the research questions regarding mentor training and monitoring of mentor programs. A focus on mentor training across numerous studies found professional development opportunities for mentor teachers, including time spent on these activities, critical in developing the skills of mentor teachers. Additionally, the monitoring of mentor programs, while not widely practiced, could provide evidence and recommendations for improving mentor programs across the states. Mentor programs have the potential to be beneficial and effective supports for both mentors and new teachers, and research continues to highlight mentoring as a critical topic in education. 


\section{SECTION FOUR:}

\section{CONTRUBUTION TO PRACTICE}

To Be Submitted to: Mentor Program Leaders at Participating Districts 


\section{Executive Summary: Mentor Program Delivery and Accountability Introduction}

With an increase in mentoring supports across the nation, a recent policy review of induction and mentoring programs by The New Teacher Center in 2012 addressed the current status of mentoring in each state. The report provided a state-by-state analysis of current mentor practices and highlighted current trends in ten criteria outlined by The New Teacher Center. The review found "multi-year induction programs accelerate the professional growth of new teachers, reduce the rate of new teacher attrition, provide a positive return on investment, and improve student learning" (Goldrick, Osta, Barlin, \& Burn, 2012, p. iii). As part of the review, Missouri's teacher induction policies were reviewed and both areas of strengths and needs were highlight by the study. The review indicated Missouri does not meet the elements of criterion seven (program delivery) and is not considered an exemplary example of criterion ten (program accountability).

\section{Methods}

A convergent parallel mixed methods approach to study mentoring programs in three select districts in the Southwest region of Missouri was completed during May of 2017. Waterman and He's (2011) suggestion for needing research in the field of mentoring which goes beyond solely quantitative data allowed the researcher to recognize the complexity of mentoring through a mixed methods approach. Responses from a total of 70 participants were analyzed from both open-ended and closed-ended questions in the form of surveys and focus group interviews. 


\section{Findings}

On average, the three participating districts reported a total of ten years' worth of providing new teachers with mentoring supports. Additionally, new teacher support is typically provided for two years. Data showed concerns regarding contact time, goals for improving formative assessment discussions, and needs for increasing classroom observations. Additionally, evidence of monitoring was reported through the use of multiple tools, however, the majority of focus group respondents recommended a need for improving the monitoring of mentoring across all three districts.

\section{Answer to Research Questions}

To what extent are elements of mentor program delivery (contact time, formative assessment, and classroom observation) and training for mentor teachers (perceptions) present in school districts across Southwest Missouri?

- Weekly contact time is the most common frequency for interactions

- Weekly discussions about formative assessments were the most common

- Classroom observations were most likely to occur once a semester

- Program leaders and mentor teachers have varying degrees of agreement regarding the training of mentor teachers

How are mentoring programs monitored across school districts in Southwest Missouri?

- Checklists, surveys, and evaluations were identified methods

- Principal check-ins and program leader meetings sometimes occurred

\section{Recommendations}

First: Identify observation options to allow for cycles of reflective conversations and provide training for mentors to support analysis of observation data. 
Second: Provide mentor training that is on-going, specific to the mentoring role, and supportive of the changing needs of mentors.

Third: Methods for monitoring mentor teachers should be reviewed and revised to include supportive tools for growth throughout the mentoring process. 

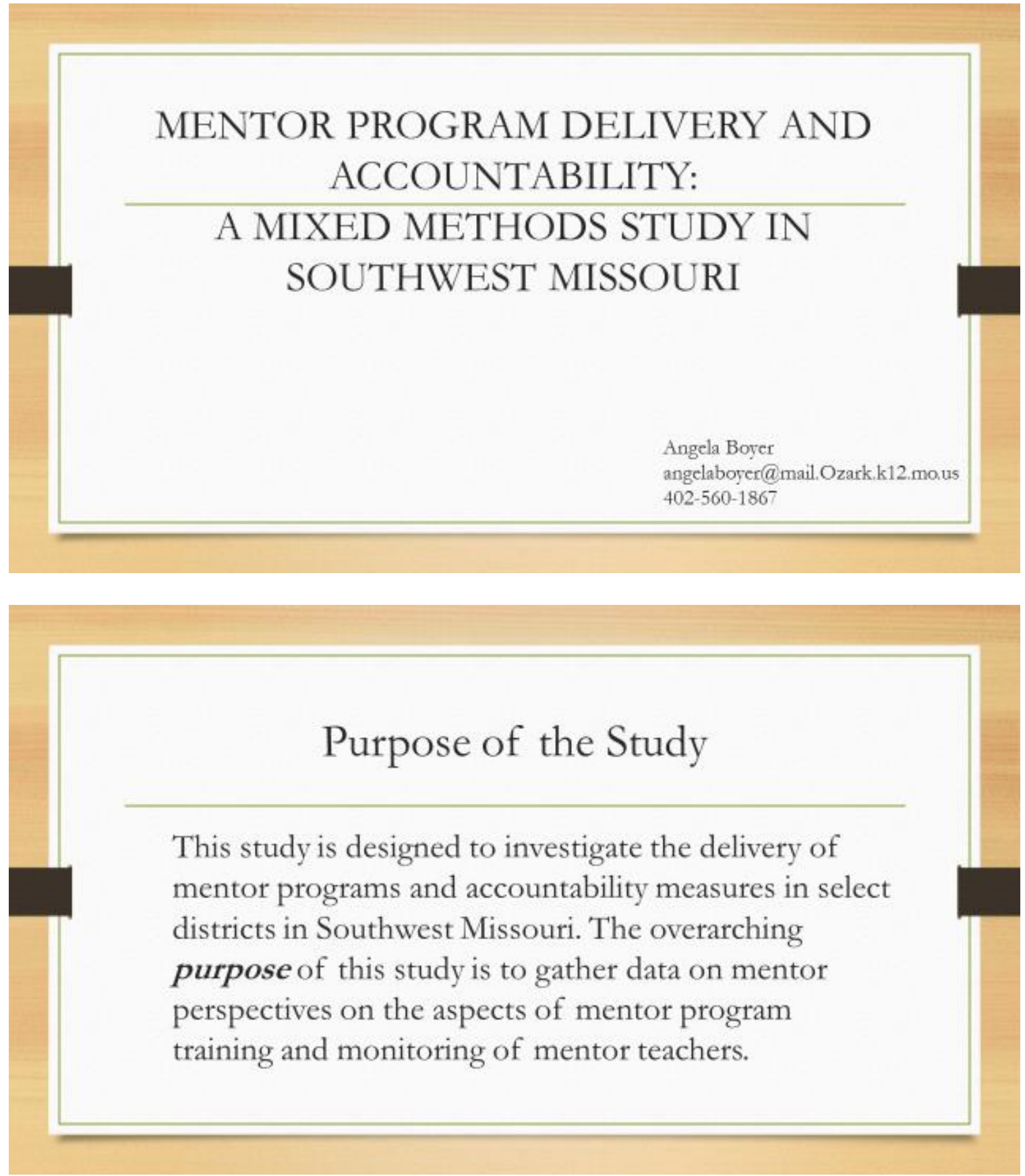


\section{Statement of the Problem}

Research has shown one of the most common forms of mentoring, an informal buddy system, lacks components of stronger mentoring methods. Mentoring which lacks effective design could produce negative results (Feiman-Nemser, 2012). Additionally, the variance in types of mentoring supports in education is cause for further dialogue (Ingersoll, 2012).

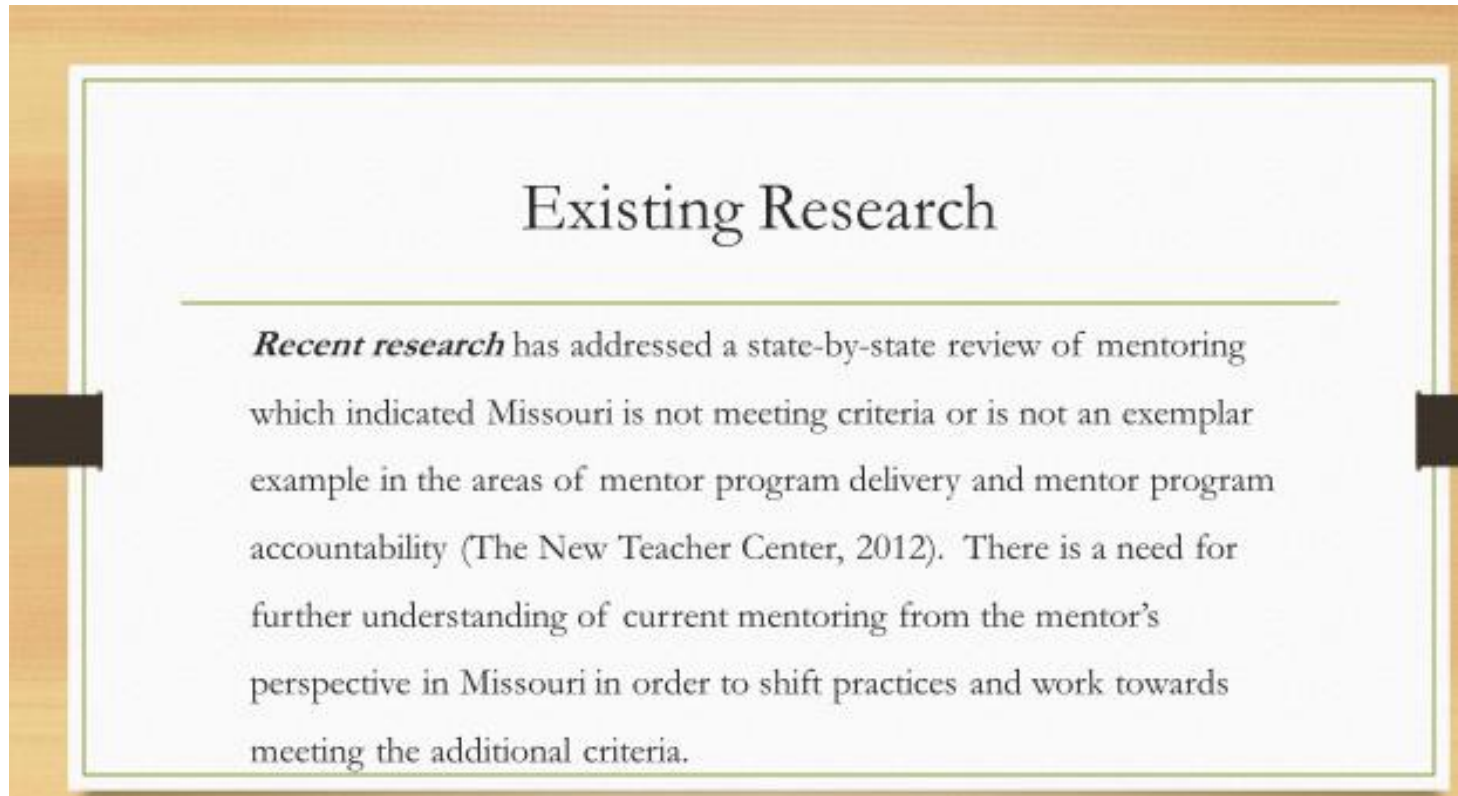




\section{Research Questions}

1. To what extent are elements of mentor program delivery (contact time, formative assessment, and classroom observation) and training for mentor teachers (perceptions) present in school districts across Southwest Missouri?

2. How are mentoring programs monitored across school districts in Southwest Missouri?

\section{Design \& Methodology}

\section{Convergent Parallel Design}

- Electronic survey for mentor program leaders (15 questions)

- Electronic survey for mentor teachers (12 questions)

- Focus group interviews with mentor teachers (10 questions)

- Mentoring documents reviewed for each district

- Data collected in May of 2017 


\section{Design \& Methodology}

\section{Participants across 3 SW Missouri Districts included:}

- 4 mentor program leaders

- 54 mentor teacher responses

- 12 focus group participants

The researcher was able to gain access to three districts with a history of providing mentoring support to new teachers. Data collected in District A and C showed mentoring as a two-year support which was provided for about 10 new teachers during the 2016-2017 school year. For District B, mentor teacher supports were being provided for 35 new teachers during the 2016-2017 school year. Additionally, District A reported 40 teachers have served in the mentoring role since 2013 and buddy teachers are assigned to second year teachers. District B currently has 3 individuals fulfilling the role of mentor teacher and approximately 20 Designated Site Supports (DSS), which has been a similar program design since before 2013. District $\mathrm{C}$ reported 25 teachers have participated in the role of mentoring over the past four years, including coaches in the role of mentors and buddy teachers for second year supports. This information provided a bank of nearly 70 mentor teachers who could be surveyed for the study in addition to the four program leaders available to survey. 
The response rate for mentor teacher surveys included 54 participants, with the number of years of providing support for new teachers most commonly between 1-3 years of support. This is evidenced in the following slide:

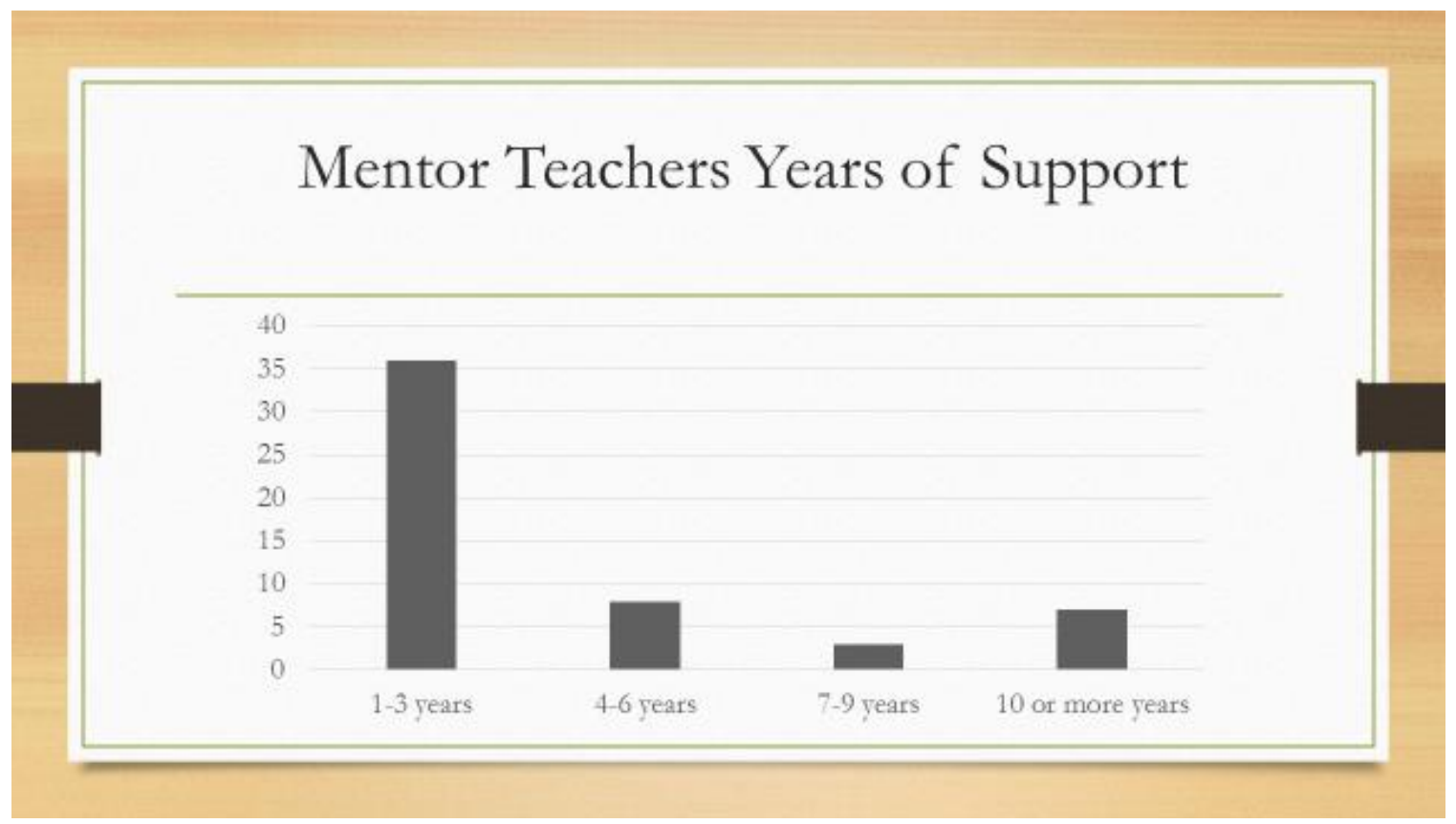

This slide illustrates 36 of the participants (67\%) have supported mentees for three years or less and $8(15 \%)$ have provided $4-6$ years of supports. Only $3(5 \%)$ of the respondents have supported in a mentoring role for $7-9$ years and $7(13 \%)$ reported 10 or more years of support.

\section{Contact Time}

The researcher was interested in the expectations for contact time between mentors and mentees at each of the sites. According to the mentor program leader survey responses, three of the responses indicated weekly contact time is allowed for mentor and mentees, while one response indicated monthly contact time. "Mentors have contact time at least twice a month with each of their new teachers for either an observation or conversation. One formal coaching cycle (with a planning conversation, an observation, 
and a reflective conversation) per year" (LS1). In the mentor teacher survey, mentors had similar responses about the contact time allowed between mentors and mentees.

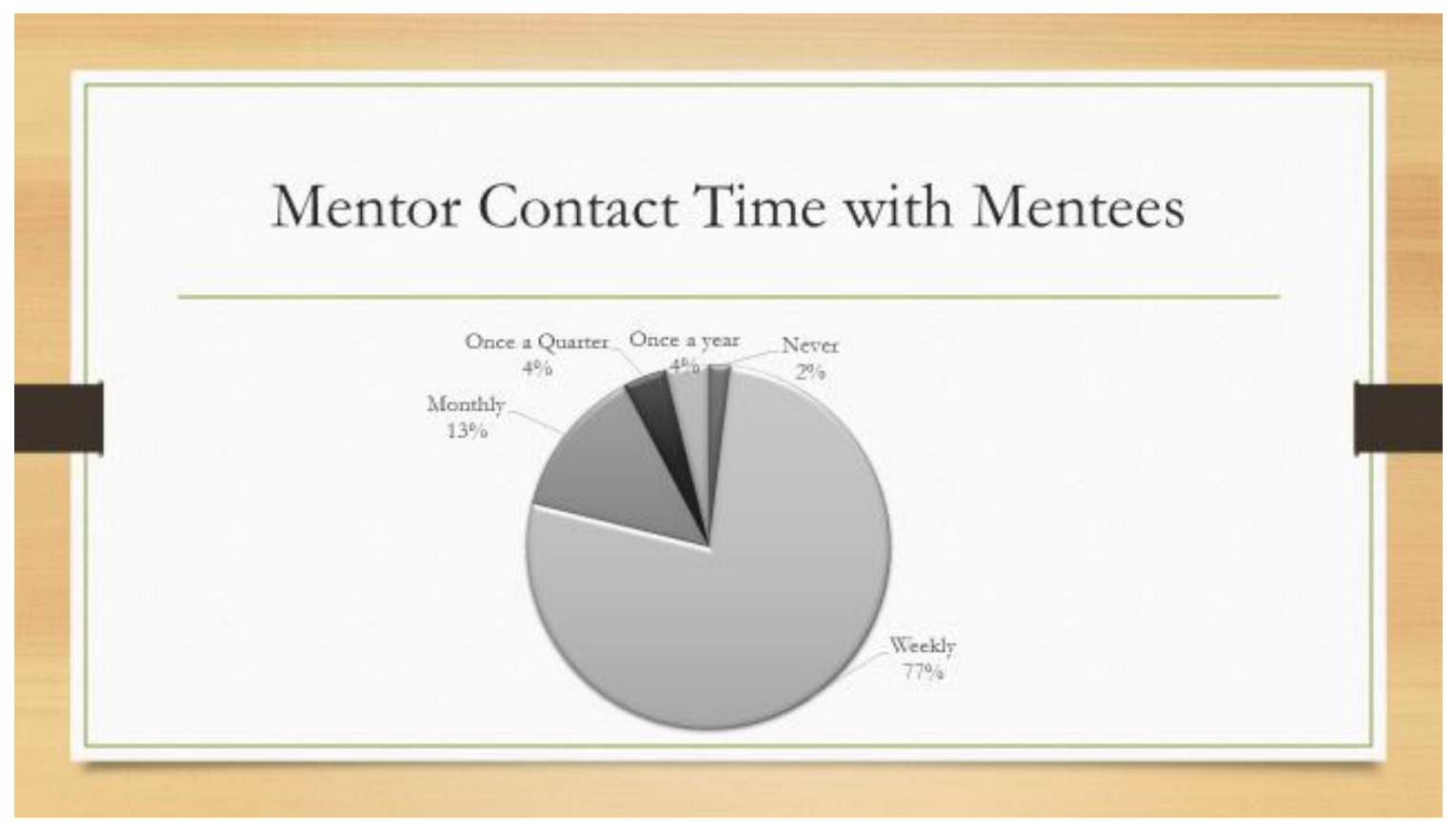

This slide illustrates weekly contact time between mentors and mentees is the most common frequency for interactions (77\%) and monthly contact time is the next most common (13\%). During focus group interviews and analysis of mentor handbooks, the researcher learned a variety of expectations for contact time across the three districts beyond weekly or monthly expectations. District $\mathrm{C}$ begins contact time with mentees through an Academy setting with at least three days of professional development for all first and second year teachers. District A begins contact time with a Mentor and Mentee luncheon at the beginning of the school year during New Teacher Week. During that time, the mentors and mentees receive the district mentoring handbook and guidelines for fulfilling the roles and responsibilities outlined for the year. The handbook states the expectation that mentors and mentees should meet monthly or more often as needed and attend quarterly mentor/mentee sessions. These contact times should be documented 
using the district mentor log and the checklists contain suggested topics to cover during interactions together.

In regards to contact time, specific examples were shared by focus group participants such as "formal sit downs at least monthly, but there's questions to answer all the time too" (FG2-4). Additionally, "As a mentor to your mentee, you are to log 12 contact hours throughout the year and as a $2^{\text {nd }}$ year $\log 6$ hours. It [contact time] can be formal or informal through email or text" (FG3-2). The importance of time to debrief and reflection through conversations with mentees as an important aspect of contact time was noted by FG2-6. Three after school trainings, as well as an opportunity for the mentor, mentee and principals to do a walkthrough together to begin contact time together was also mentioned by a participant (FG1-1).

Additional data collected focused on contact time showed concerns from mentor teacher survey responses regarding when and how the expectations for contact is completed. "All of my mentor time is done on my plan time, or before and after school" (MS22). Another participant noted, "The program is always best when the two teachers work at the same building. It is hard to make schedules work when you are trying to cross over buildings and grade levels" (MS1). Similarly, "Contact time is limited due to schedules and daily demands of the job. The only way I was able to observe my mentee teacher was because I had a student teacher at the time" (MS17). While The New Teacher Center acknowledges requirements in the school day could cause concerns for contact time between mentors and mentees, it is important for districts to have clear expectations for providing weekly or monthly contact opportunities and to provide guidelines for fulfilling those expectations. It should also be noted that District B has two 
full-release mentors in part-time positions and numerous DSS positions providing mentor supports while District A and C have teachers and coaches fulfilling the mentoring roles on top of teaching responsibilities.

\section{Formative Assessment}

Another focus of the research was on the frequency in which mentor and mentees discuss formative assessment. According to the mentor program leader survey responses, three of the responses indicated mentors discuss formative assessments with their mentee once a quarter, while one response indicated monthly discussions. Further, "Formative assessments are discussed as needed, but there is no specific guideline" (LS1) and "clarity regarding formative assessments [is] not spelled out...[in the handbook]" (LS4). In the mentor teacher survey, mentors had a range of responses about the frequency in which mentors and mentees discussed formative assessments.

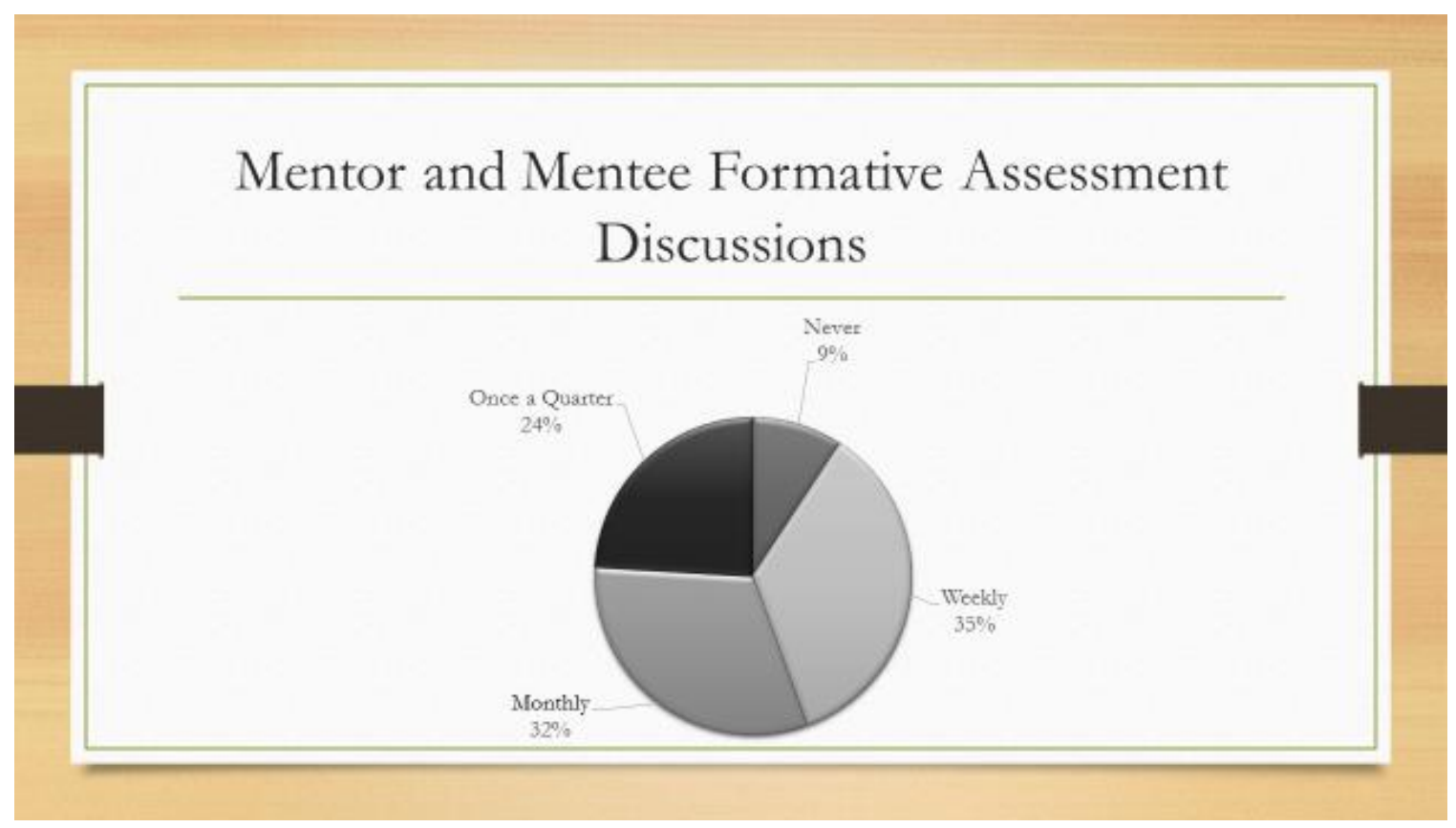

The above slide shows the frequency in which mentors indicated formative assessment discussions. Weekly discussions about formative assessments were found to 
be the most common frequency for interactions (35\%) and monthly discussions about formative assessments was the next most common (32\%). An additional 24\% of participants indicated once a quarter as the frequency in which formative assessments are discussed and 9\% indicated formative assessments are never discussed between the mentor and mentee. Further, during focus group interviews, FG3-1 and FG3-3 both shared their coaching role with new teachers provides opportunities for a focus on formative assessments, however, neither shared there was a mentoring expectation for discussing formative assessments with their mentees. "In my role [coaching role], that's what I do all day every day...it's how we build on instruction. As a teacher mentor though, the early out PLC time is when we have these casual conversations about practices and formative assessments" (FG3-3). Similarly, "In my lit coach position, we use our team meetings to discuss [formative assessments] and we are growing with that in becoming more formulated each quarter" (FG3-1).

In regards to discussing formative assessments with their mentee, one participant shared, "I was not being specific enough- I needed to help my mentee write ideas for using formative assessment checks into her lesson plans...I think it helped a little bit more than me telling her to try this and this and this" (FG2-1). Similarly, another participant noted formative assessments can be "very vague, so sometimes I help set those up- what they look like and 2-3 different ways how they could use them" (FG2-5). Further, participants in focus group one shared that although the district curriculum has become heavy with formative assessments, the mentor role does not include a structure or clear role to talk about formative assessments. However, both high school level mentor 
teachers in the focus groups indicated a greater focus on mentoring through conversations about formative assessments with their mentees.

Overall, having collaborative conversations about formative assessments was identified by mentor teacher participants as a way to learn what ideas new teachers are bringing with them to the profession and a way to share ideas across teams of veteran and new teachers alike. A goal of including formative assessments into mentoring conversations would be to support mentees in ways to analyze data and plan for the next steps of instruction. Both PLC times and coaching supports for discussing formative assessments surfaced throughout the responses for mentor surveys and focus group responses as a primary mode for supporting new teachers with those discussions.

\section{Classroom Observation}

A third component of the first research question guiding this study was focused on the frequency in which mentor teachers observed the assigned mentee. According to the mentor program leader survey responses, two of the responses indicated mentors observe mentees on a monthly basis, while the other two responses indicated observations occurred once a semester. LS3 and LS4 both indicated the mentor program handbook provided clear expectations for observations, however the mentor teacher surveys indicated a range of responses about the frequency in which mentors observed their mentee during instruction (see slide below). 


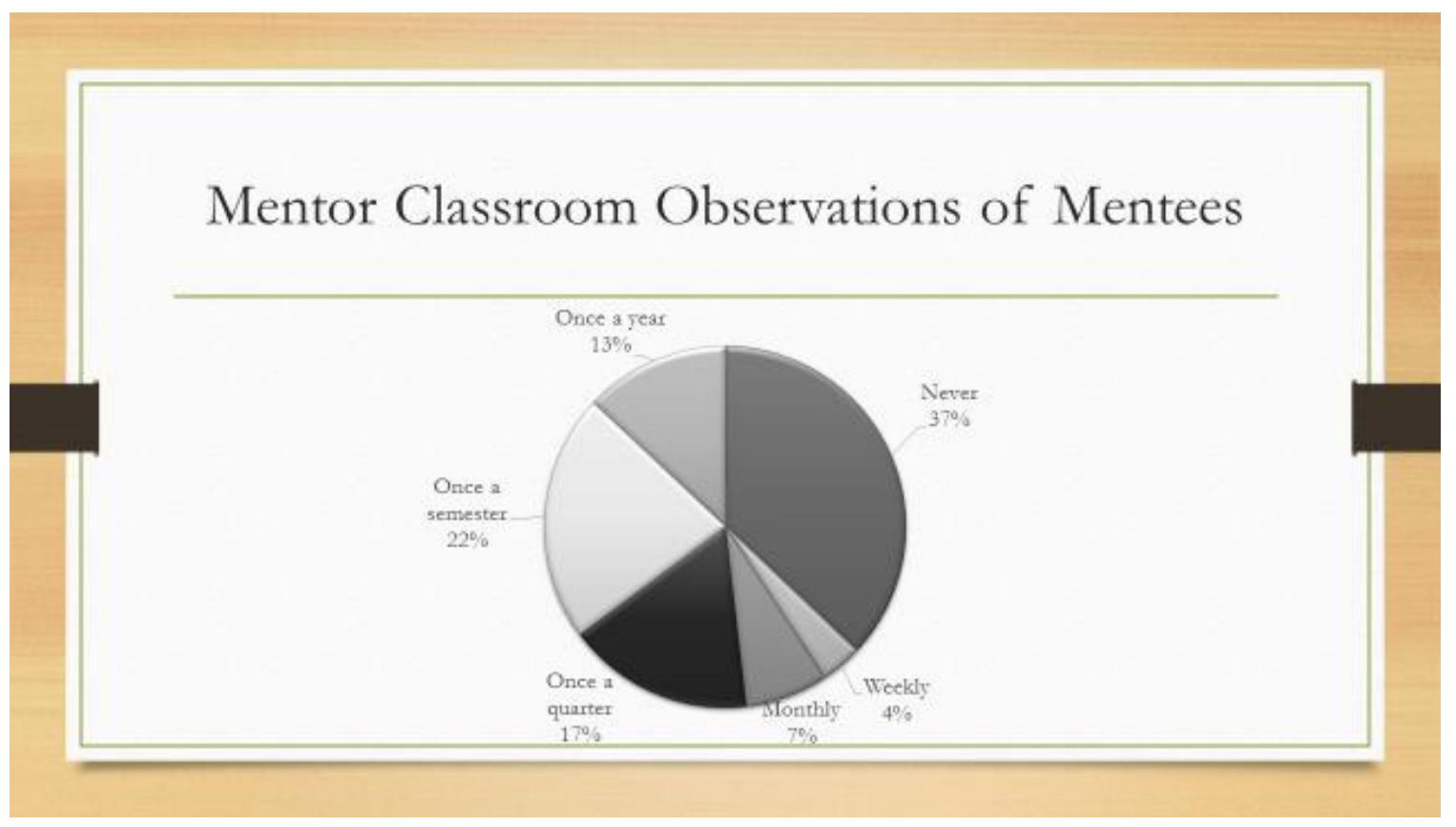

This slide illustrates $37 \%$ of mentors reported they never observe the mentee during instruction. An additional $22 \%$ of participants indicated once a semester as the frequency in which observations occur and $17 \%$ indicated once a quarter. Once a year observations were reported as the frequency for $13 \%$ of the participants, with the remaining $11 \%$ being either weekly or monthly observations. One participant shared, "I was not provided any time to observe my new teacher" (MS46). Similarly, another noted, "I was disappointed that I was not able to observe my mentee. I think it would have been very helpful for us both" (MS53). In response to the expectation for observing mentees, a respondent shared, "Observation was hard as I am teaching the same times my mentee was teaching proving difficult for me to get into the classroom to observe her" (MS10).

During focus group interviews, one participant noted the following about their role observing new teachers: "My observations are awesome because I have a template that I have created for myself and because I am non-evaluative, I'm still a buddy, a go- 
between, liaison, and still trusted, my observations are when teachers call me in. I also set up a schedule for teachers to observe each other. We do have a template in our handbook for logging hours spent with our teachers but not an observation form" (FG33). From a different standpoint, a respondent noted, "As a mentor program we don't have anything like that [observation form]... it is something we should create if it isn't too binding" (FG3-2). Similarly, another participant indicated a flexible mentoring style for observations which included both scheduled and pop-in observations without the use of specific form (FG1-2).

Additionally, one participant noted, "I have not done that [observation of mentee]...been modeling and partnering alongside but have been spending time building rapport" (FG3-1). Further, the same participant shared district collected surveys provide mentor leaders with information about how the mentoring supports are progressing throughout the year. In one survey response, this participant mentioned the majority of mentoring supports, such as observations, were not coming from an assigned mentor but rather someone else the new teacher had built a connection with.

Another aspect noted by focus group participants was the need to make it clear that the mentor observations are not an evaluation and are not meant to be "stressful or threatening." Further, FG2-6 shared that providing options for how the observations are completed once trust has been build can be beneficial to meeting the observation expectations. An example of how mentor teacher reported being able to complete the observation expectations included a sub provided for the mentee to spend the day with the mentor alongside a coach for debriefing and reflection. District $\mathrm{C}$ also provides the following handbook guidelines: "The building administrator should provide several 
opportunities for the mentor to visit the beginning teacher's classroom during instructional times to complete the observation/feedback cycle. Allowing mentors to observe mentees will improve the systematic approach to developing and retaining highly qualified staff."

When mentor teachers responded to the guidelines for all three components of contact time, formative assessment, and observation in an open-ended question, a variety of responses across the participants were received. A common response included expectations being provided in a handbook or binder or meeting for contact time and observations. More specific responses included "Contact time is necessary, I met daily and observations were expected quarterly in our handbook" (MS6) and "We were emailed a booklet of talking points for each month, but I felt most of them didn't apply to the role my mentee and I serve" (MS4). A similar concern from another mentor teacher included, "There are required activities and checklists that mentor and mentee must complete...I feel that other than the one hour PD and a binder of information that teachers have little time to read there is not a lot of accountability until assignments are due at the end of the year" (MS29).

\section{Training for Mentor Teachers}

An additional consideration of the mentor training supports provided for each district was collected in the surveys and focus group interviews to further inform the research. A variety of focus group responses indicated either a lack of mentor training or training opportunities in the regular teacher role which informed and supported the mentor. For example, one participant shared they do not believe District B has organized training for mentor teachers, but says there are opportunities to receive "on-going training 
in order to be able to mentor people in the area of literacy, Adaptive Schools training, and Cognitive Coach training" which have all helped with developing their mentoring (FG3$1)$.

While District C's handbook requires mentor teachers to provide support in the areas of curriculum, instructional strategies, classroom management, policies and procedures, and more, respondents were not able to identify specific mentor training to support in learning more about these areas. Additionally, the mentors are expected to offer cognitive coaching skills and collaborative training, which a handful of mentors mentioned as a helpful support they received training in for their role outside of mentoring. Further, District B's handbook includes the completion of the BTAP (Beginning Teacher Assistance Program) and classroom coaching as expectations for the mentor teachers. The focus group one participants were eager to continue using cognitive coach training and cooperative learning training in addition to CHAMPS training to support their mentoring role next school year.

Additionally, 50\% of mentor program leaders indicated that 0-5 hours of training would occur for training mentor teachers and 25\% reported 6-10 hours of training. One respondent indicated 21 or more hours would be provided for training mentor teachers. Similarly, a large proportion of mentor teachers (87\%) reported they received 0-10 hours of training for their mentoring role. Further, mentor teacher survey responses indicated an interest in training to help mentors provide supports around the following topics: planning, classroom management, instructional practices, communication tools/ideas, data analysis, and professional plans or evaluation supports. 
The majority of focus group participants identified they were asked or told to fulfill the mentoring role by a principal or supervisor, but were not clear on training that directly supported their mentoring role. There was also a need for on-going training and check-ins for both the mentor and mentees, either separately or collaboratively. There were several responses related to coaches being the trained or expert content resource for new teachers rather than the mentor teacher. Overall, the data indicated a need for ongoing training for both conducting observations and discussing formative assessment, moving beyond checklists and logs of activities. More specifically, one participant shared "It would be helpful to have more than a one hour PD in which we were given a binder of info and assignments and told to review it on our own time. It would be good to have at least quarterly PD to check in and review requirements in smaller chunks of information" (MS29). Similarly, MS35 noted "I believe a time (maybe quarterly) that new teachers can get together and discuss experiences/questions with other new teachers and mentors would be beneficial."

Additionally, one portion of the survey for both the mentor program leaders and the mentor teachers asked participants to what extent they agreed with mentor training being in place for mentors. The survey responses are shown in the following two slides: 


\section{Training for Mentor Teachers: Program Leader Perceptions}

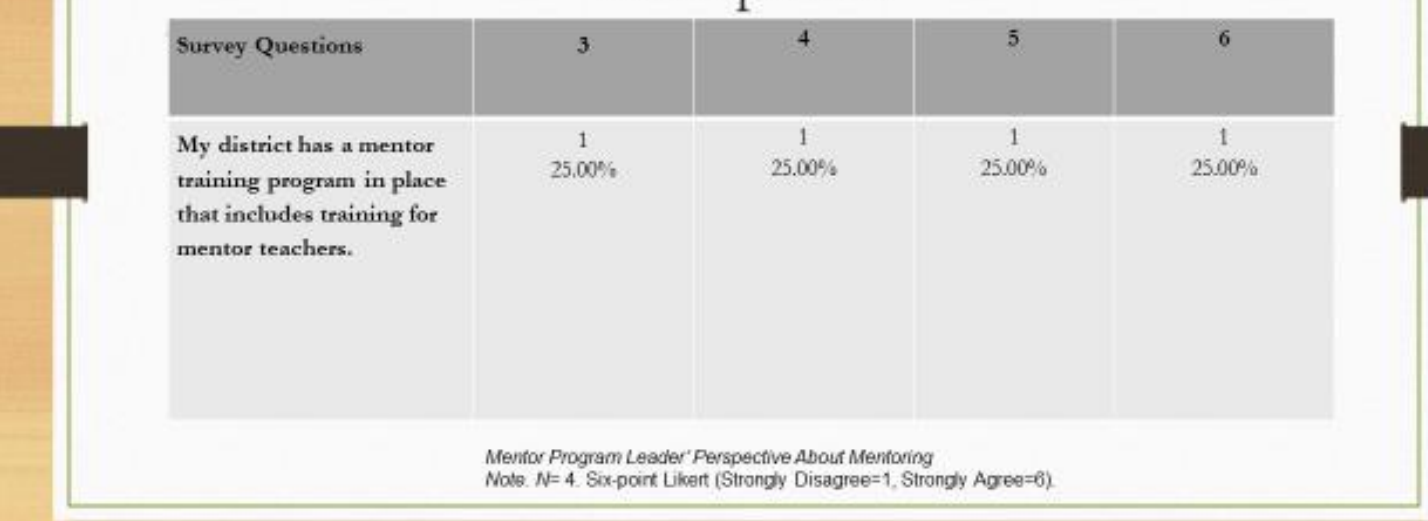

The mentor program leader responses show varying degrees of agreement from slightly disagree to strongly agree regarding training programs being in place for training mentor teachers. Similarly, the mentor teacher responses span from strong disagreement to strong agreement with almost $70 \%$ of respondents believing their district does have a mentor training program in place to prepare mentors for the role.

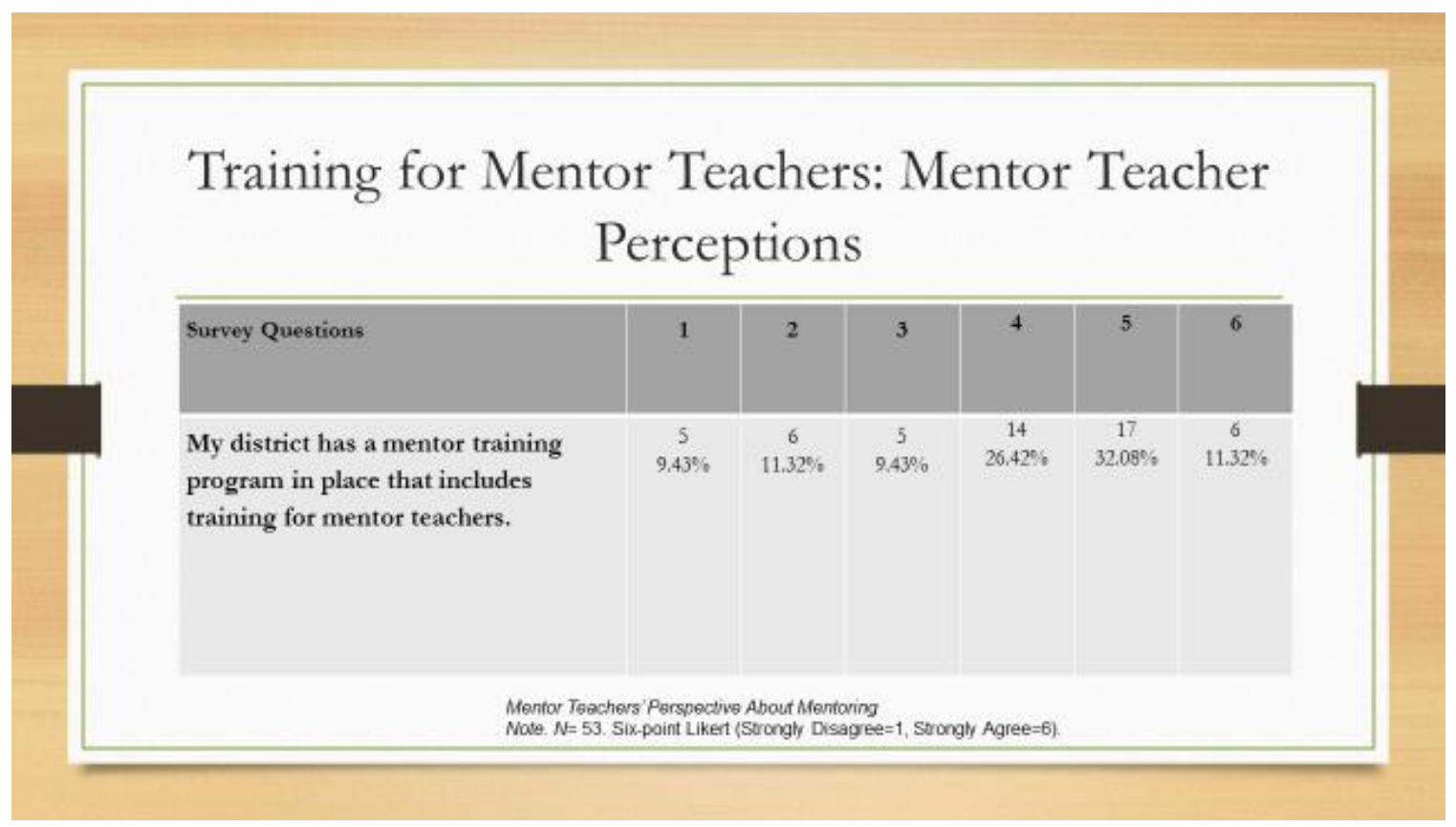




\section{Summary of the Findings: RQ1}

To what extent are elements of mentor program delivery (contact time, formative assessment, and classroom observation) and training for mentor teachers (perceptions) present in school districts across Southwest Missouri?

- Weekly contact time between mentors and mentees is the most common frequency for interactions

- Weekly discussions about formative assessments were the most common frequency for interactions

- Classroom observations were most likely to occur once a semester or not at all

- Program leaders and mentor teachers have varying degrees of agreement regarding the training of mentor teachers

\section{Monitoring of Mentor Programs}

The researcher was also interested in the monitoring of mentor programs across the three districts. According to the mentor program leader survey responses, one participant noted "Throughout the year, new teachers are asked about what is beneficial to them...Mentors discuss with each other what is going well or not. An end of year reflective conversation is had with new teachers including an evaluation of the program" (LS1). Additionally, another leader shared "We use checklists for all new hires, mentors, and DSS to complete" (LS2) and surveys or evaluations are used to "monitor and adjust" mentor program supports according to LS4.

Mentor teacher survey responses showed, "In the handbook given to both the Mentor/Mentee, a clearly defined monthly check-off list is included with certain tasks to do together" (MS5). In regards to their mentor program being monitored, one participant indicated, "Not at all, other than turning in my checklist at the end of the year" (MS11). Similarly, another response shared "District office provides scope and sequence of 
expected time and topics to be covered. I do not know how this data is used once it's returned to district at the end of the year" (MS16) and another noted, "We have used surveys in the past. I am hoping we start doing interviews to see how well the program is appreciated with our new teachers" (MS20). In a review of District A's handbook, guidance in the form of checklists included a before school checklist, a teacher workshop week checklist, first day checklist, monthly checklists, and observation checklists. These checklists guide mentors to discuss topics such as procedures, parent communication, building relationships, curriculum, student discipline, and more. Additionally, District A's mentoring handbook indicates both a Mentee Exit Survey and Mentor Exit Questionnaire is part of the yearly monitoring of mentoring.

During focus group interviews, one participant mentioned, 'I've seen a progression to a much more monitored and more intentional approach to our mentoring system. I think we still have some bridges to cross, but we are much more intentional...what we are doing in our new teacher academies is a good example of that" (FG3-3). Two additional responses focused on the monitoring of mentoring through principal check-ins, email reminders, and collected notes by the principal (FG2-1 and FG2-4). Beyond monitoring examples by principals, another respondent indicated the mentor program leader meets monthly with mentees to check on how visits with mentees are going and to address any issues or provided any needed resources the mentors may need (FG1-2). The majority of focus group respondents indicated the monitoring of mentoring as an area needing improvement. Specifically, FG2-2 noted an idea for coming together "mid-year as a mentoring group to support or encourage each other." 


\section{Summary of the Findings: RQ2}

How are mentoring programs monitored across school districts in Southwest Missouri?

- Checklists, surveys, evaluations, and questionnaires were mentioned as methods for monitoring mentoring across the three districts

- Principal check-ins, collections of notes, and program leader meetings with mentors each occurred at least in one district

- The majority of focus group respondents indicated the monitoring of mentoring as an area needing improvement.

\section{Recommendations}

\section{Recommendation \#1}

First: Identify observation options to allow for cycles of reflective conversations and provide training for mentors to support analysis of observation data.

- Guidelines for classroom observations by mentor teachers are outlined for all three districts in this study, however supports and training for observations are lacking consistency.

- Program leaders identified monthly or semester observations with observation logs

- Mentor teacher responses showed a large amount of mentors never conducting classroom observations or recording notes from the observation.

- Focus group participants had a variety of coverage options or forms used for observations, but indicated a need for more guidance in this area.

It is apparent that guidelines for classroom observations by mentor teachers are outlined for all three districts in this study, however supports and training for observations are lacking consistency. While program leaders identified monthly or 
semester observations with observation logs, mentor teacher responses showed a large amount of mentors never conducting classroom observations or recording notes from the observation. Further, focus group participants had a variety of coverage options or forms used for observations, but indicated a need for more guidance in this area. By targeting classroom observations as an area of needed improvement, each of the three school districts could improve observation practices between mentors and mentees.

With the recommendation from The New Teacher Center (2012) to provide cycles of observations which allow for reflection and analysis of the data, it would be helpful for districts to provide training focused on these aspects. Districts could gather data about current forms and reflection tools used by mentor teachers to gain information about what tools are working. Districts could also identify options for conducting classroom observations which offer choice and coverage for the teachers involved. If districts could identify the "how" and "why" and articulate the importance of mentor observations to mentors and mentees, the first step of collecting observation data could increase in a more systematic manner in each district. Additional professional development for mentor teachers from administrators, coaches, or program leaders could be utilized to dive into the analysis of the observation data once cycles of reflection have begun. 


\section{Recommendation \#2}

Provide mentor training that is on-going, specific to the mentoring role, and supportive of the changing needs of mentors.

- Districts had a variety of guidelines for providing mentor training with an emphasis on primarily providing beginning of the year training

- Mentor teacher responses showed a need for supports a variety of topics which could change during each year of mentoring.

- Focus group participants most often received training for teaching or instructional coaching roles that supported their mentoring rather than specific mentor training.

A variety of responses regarding mentor training across the three districts suggests a need for a recommendation related to training. Similar to research by Ganser (2001) which suggests that training often tapers off after beginning of the year training sessions, mentor teacher responses indicated a need for on-going training. More specifically, participants indicated a need for training focused on a variety of topics and issues in mentoring with input as to changing needs throughout the year. Each of the districts could benefit from increasing the types of training offered specifically to mentor teachers and the frequency in which training supports are provided. 


\section{Recommendation \#3}

Methods for monitoring mentor teachers should be reviewed and revised to include supportive tools for growth throughout the mentoring process.

- Increased monitoring of mentor programs could be beneficial to improving mentor practices.

- Mentor survey respondents struggled to provide opportunities where monitoring supported them in growing as a mentor teacher. Mentors indicated support sessions or on-going training based on topics of interest or concern as a measure to monitor progress throughout the year could be beneficial.

- Support throughout the mentoring process could be more supportive than turning in a log or survey at the end and then reactively making changes for the following year.

Mentor teachers in both surveys and focus group interviews indicated that increased monitoring of mentor programs could be beneficial to improving mentor practices. Mentor teachers identified checklists, surveys, or leaders who occasionally monitored mentoring as the main method for gathering feedback about mentoring supports in each district. Mentor survey respondents struggled to provide opportunities where monitoring supported them in growing as a mentor teacher. Mentors indicated support sessions or on-going training based on topics of interest or concern as a measure to monitor progress throughout the year could be beneficial. This would provide support throughout the process rather than turning in a log or survey at the end and then reactively making changes for the following year. 
SECTION FIVE:

CONTRIBUTION TO SCHOLARSHIP

TO BE SUMITTED TO:

INTERNATIONAL JOURNAL OF MENTORING AND COACHING IN EDUCATION 
Mentor Program Delivery and Accountability:

Perspectives from Program Leaders and Teachers 


\section{Structured Abstract}

\section{Purpose}

The purpose of this research is to go beyond quantitative studies focused on the mentee, instead also including the perspectives of mentor program leaders and mentor teachers. Based on recommendations by The New Teacher Center's policy review of program delivery and accountability, researchers identified areas needing further consideration for numerous states.

\section{Design/methodology/approach}

Through a mixed methods approach, the research offers insight about current aspects of mentor program delivery and accountability across multiple districts in Southwest Missouri, specifically concerning contact time, formative assessment, and classroom observation. Both mentor program leaders and mentor teachers provided perspectives about delivery and monitoring of mentor programs.

\section{Findings}

The research paper shares findings from both mentor program leaders and mentor teachers across three districts in Missouri showing that $77 \%$ of respondents met weekly with their mentors while formative assessments were less uniform, being about evenly split between weekly, monthly, or quarterly. Classroom observations did not occur 37\% of the time, and was generally infrequent when it did occur. The themes which emerged from the focus group included providing options and defined roles for observations and increased monitoring. 


\section{Research limitations/implications}

The research implications focus primarily on a need for further discussion around classroom observations and on-going monitoring.

\section{Originality/value}

With a rise in mentoring programs and supports for new teachers since the 1990s, variations in the delivery and monitoring of mentoring programs offer cause for better informed discussion.

Keywords: Mentoring, Mentor program leaders, Mentor teachers, Program delivery, Program accountability, The New Teacher Center 


\section{Introduction and Background}

Since the 1960s and 1970s, formal mentoring programs emerged which included support and assistance for new teachers struggling with the challenges of uneven school policies and procedures (Ganser, 2005). While mentoring programs have continued to be influenced by evolving professional standards and policies for teacher induction, the significance of mentoring programs for teachers has grown exponentially. With an increase in mentor activity rising from $40 \%$ to $89.4 \%$ since the 1990s (Feiman-Nemser, 2012), current research shows more than half of the states require teachers to participate in mentoring or induction programs to some degree (The New Teacher Center, 2012).

Ingersoll (2012) found $91 \%$ of beginning teachers reported they received support from an induction program as of 2008 , however, the variance in the types of mentoring supports is a cause for dialogue in education (Ingersoll, 2012). Casey and Claunch (2005) also noted that while mature, successful programs can be found in some states and school districts, the mentoring of beginning teachers is a long ways from being fully institutionalized in public education. A recent policy review of induction and mentoring programs by The New Teacher Center in 2012 addresses the current status of mentoring in each state. The report not only provided a state-by-state analysis of current mentor practices but also highlighted current trends in ten criteria outlined by The New Teacher

Center. A major finding from the review of state policy showed, "multi-year induction programs accelerate the professional growth of new teachers, reduce the rate of new teacher attrition, provide a positive return on investment, and improve student learning" (Goldrick, Osta, Barlin, \& Burn, 2012, p. iii). 
Additionally, The New Teacher Center (2012) noted that state policies have broad influence on local induction programs. The premise for the ten criteria utilized in the policy review indicated states meeting more of the criteria would help new educators receive sufficient levels of induction and mentoring support to enhance teacher effectiveness. The first two criteria advocate for all teachers and school administrators to receive two years of induction support. Criterion three states a requirement for formal program standards to guide the design and operation of mentoring programs. Criteria four through six focus on rigorous selection and ongoing training of mentor teachers, in addition to considerations about the assignments and caseloads of mentor teachers. Criterion seven is focused on the program elements, including considerations for contact time between mentors and new teachers, formative assessment of teaching practice, and classroom observations. Criterion eight suggests funding as a component for supporting induction programs. Finally, criteria nine and ten focus on accountability of the education and program, and suggests assessing or monitoring program quality should occur through evaluation, surveys, site visits, and other tools.

\section{Purpose and Context of the Study}

Effective partnering of a mentor and mentee can have positive lifelong impacts for new teachers (Ganser, 2005). However, even with a rise in mentoring supports, research by Athanases, et al. (2008) found induction programs in the United States rely on impoverished models. Further, research by Ingersoll (2002) has indicated one-third of beginning teachers do not remain in the profession beyond the first three years of service, and $43 \%$ of beginning teachers identified a lack of adequate support as a key factor impacting the first three years in the profession. In 2012, The New Teacher Center's 
policy review of induction and mentoring programs found there are only three states currently meeting the majority of the mentoring criteria, as outlined by The New Teacher Center: Connecticut, Delaware, and Iowa.

The New Teacher Center's policy review of Missouri became the primary interest for the researcher. According to The New Teacher Center's review, Missouri did not meet the elements of criterion seven (program delivery) and was not considered an exemplary example of criterion ten (program accountability). Further, while Missouri is one of several states which does not quantify a minimum amount of contact time for mentor-mentee interactions, the standards include the element of release time for observations and a minimum requirement of three meetings each year. The New Teacher Center (2012) emphasized that sufficient time for mentoring relationships undermines policy, programmatic intent, new teacher effectiveness, and student achievement. The New Teacher Center (2012) encouraged "raising expectations through finding researchbased program elements" as part of criterion seven. Currently, the Missouri mentor program standards do not specify the critical element of formative assessment. This standard, when implemented, could include the process of data collection and collaborative conversations between the mentor and mentee, allowing for discussion around research-based practices. The policy review indicated 16 states currently have this component in place and the importance of the implementation of this element as a means to impact individual teacher performance.

The final component of criterion seven is classroom observation, which The New Teacher Center (2012) emphasized particularly with a need for training in data collection, analysis, and interpretation experience with classroom observation and formative 
assessment. Missouri is one of 25 states which provides release time as a

recommendation to allow for observations to occur for mentors and mentees.

Additionally, class schedules for the mentor and mentee are recommended to align to allow for sufficient observation time.

In addition to criterion seven, there was a need to study program accountability (criteria ten). This component included the monitoring of mentor programs through the use of evaluation, surveys, site visits, and self-reports. The Missouri standards included recommendations on gathering feedback in the form of pre and post surveys as well as exit interviews. Since the 1990s, there has been a rise in evaluation techniques for reviewing and monitoring the quality of mentoring programs. These techniques have begun to include more about learning results and the impact of mentoring programs (Ganser, 2005). The New Teacher Center (2012) encouraged the leaders of mentor programs to evaluate existing program elements and identify shifts needed to better meet the needs of mentors and new teachers.

Additional existing literature refers to mentors using a variety of metaphors, many of which lack guidance on what mentoring actually entails. An understanding of the roles and features of mentoring can help demonstrate the complex and dynamic relationship between adult learners. Descriptions of the role of the mentor, while often varied, have included providing classroom observations and feedback, engaging in discussion, locating materials and providing general information, and being a liaison for the mentee (Lieberman, Hanson, \& Gless, 2012). Schien (1978) described mentoring roles as being similar to a coach, developer of talent, opener of doors, or protector. Galvez-Hjornevik (1986) described mentors as trusted guides and counselors, 
while Borko (1986) used more traditional terms such as helper, peer, or support teacher. Additionally, George, Sims McLean, and Mayer (2007/2011) included aspects of mutual learning, exploration of similar values, and shared enjoyment in describing the importance of a life-changing mentor.

While the models for mentoring new teachers are complex and training opportunities for mentor teachers are varied, one of the consistent theories recognized in literature about mentoring is the connection to adult learning theory. With a primary focus in this study on the mentor teacher, Casey and Claunch's (2005) ideas about the need for recognizing the growth which occurs for the mentor teacher as they change from primarily being knowledgeable about content knowledge to gaining professional knowledge apply.

In a classic work, Levinson (1978) described mentoring as a "model of adult conduct" defined by acts of both giving and receiving. Additionally, Levinson suggested focusing on the character of the relationship rather than the formality tied to mentor roles using more of a cyclical model of mentoring. In The New Teacher Center's (2012) expectations for interactions between mentors and mentees, criteria seven specifies interactions to include contact time, conversations about formative assessment, and classroom observations. More specifically, providing sufficient time and focused efforts on what the mentoring could look like is woven throughout criteria seven. According to The New Teacher Center (2012), the frequency and duration of mentor-mentee contact time is one of design elements most associated with impacts on teaching effectiveness and student learning. Additionally, The New Teacher Center's expectations for 
formative assessment are grounded in the belief that teacher development must involve using assessment data to guide the support of beginning teachers.

\section{Contact Time}

The New Teacher Center (2012) suggests frequent and meaningful interactions to help maintain policy and program intentions. More specifically, contact time offers mentors and mentees opportunities to develop experiences focused on instruction either on a weekly, monthly, quarterly, or semester basis. Several states have either indicated specific contact time requirements or conditions for supporting this aspect for mentors and their mentees. According to the state-by-state study, North Carolina limits preparations, non-instructional duties, and additional assignments for new teachers to allow for contact time. The New Teacher Center's (2012) findings about Maryland's contact time policy included the requirement of regularly scheduled meetings, observations, and co-teaching opportunities for the mentee with a skilled mentor. Additionally, Arkansas policy focused on weekly contact hours and 25 additional hours per semester while Kentucky has a minimum of 20 hours of classroom contact and 50 hours of outside of the classroom contact between the mentor and mentee (The New Teacher Center, 2012). While many states have expectations for contact time between mentors and mentees, the use of full-release mentors have also shown to provide more of the necessary time for collaboration between new teachers and their mentors.

\section{Formative Assessment}

A skilled mentor can be the key to leading conversations about how to analyze data and collaboratively plan for the next steps of instruction. More specifically, the mentoring relationship can support The New Teacher Center's (2012) three elements for 
formative assessment which include standards for best practice, criteria for measuring growth, and evidence of achievement. In California, induction programs require three similar elements in order to develop a collaborative plan to guide professional growth of the mentee through data collection focused on practices and tools to identify the progress. According to The New Teacher Center (2012), South Carolina requires mentor-guided formative assessment which can help the mentee focus on reflection of teaching, areas of need or concern, and aspects of professional development. While The New Teacher Center noted at least 16 states have a focus on formative assessment aspects as part of induction, its importance is at the core of the work of mentors only if it affects individual teacher performance.

\section{Classroom Observation}

Another critical aspect for supporting new teachers through mentoring is the element of classroom observation including an iterative cycle of observations, feedback and discussion. Further, the observations should be intentional, and mentors should have experience with protocols for data collection, analysis, and interpretation. According to The New Teacher Center's policy review (2012), Delaware's induction expectations include a three-year framework with cycles of observations, post-observation meetings, video review, workshops, and self-reflections. Another induction example from West Virginia indicated mentor observations for one hour per week during the first half of the school year and then bi-weekly during the second part of the school year in addition to joint planning periods for the mentor and mentee. The New Teacher Center noted over half of the states require some level of classroom observations, but there is considerable variance across the states. Overall, The New Teacher Center (2012) indicated nine states 
have induction program expectations for contact time, formative assessment, and classroom observations outlined to some degree.

\section{Design of the Study}

The researcher selected a convergent parallel mixed methods approach to study mentoring program delivery and accountability in select districts in the Southwest region of Missouri. With this selected design, the researcher was able to collect both quantitative and qualitative data at the same time (Creswell, 2014). Waterman and He (2011) noted mentoring research designs are typically comprised of quantitative data which is then analyzed through statistical measures. However, Waterman and He (2011) discussed that the research needed in the field of mentoring goes beyond quantitative data, including data which recognizes context and the complexity of mentoring. Consequently, the goal for data collected in this study was a mixed methods approach which included both closed and open-ended survey questions and focus group interviews.

\section{Research Questions}

Two research questions guided data collection and analyses in the study. Both questions were addressed through mixed methods inquiry.

1. To what extent are elements of mentor program delivery (contact time, formative assessment, and classroom observation) present in school districts across Southwest Missouri?

2. How are mentoring programs monitored across school districts in Southwest Missouri?

\section{Setting}


The researchers collected and analyzed data from a specific subset of districts in Missouri. For the purpose of this study, a setting within Southwest Missouri was selected due to the proximity to the researchers and to limit the sample size within one region. This provided the researchers with three different mentoring programs and groups of mentor teachers at each district available to participate in surveys and focus group interviews. District A served nearly 5,800 students and District B served nearly 4,700 students while District C had an enrollment of 2200 students as of 2016 in grades K-12.

\section{Participants}

During the first survey portion of the study, one participant from each of the selected districts was contacted to participate in the study. The intended contact for the survey was the district employee(s) or department head(s) assigned to supervise mentoring or induction programs. The researchers utilized the initial survey in order to gain data regarding which elements of mentoring program delivery and accountability are currently present in each of the respective programs. Additionally, these individuals were the gatekeepers for providing existing documents and contacts to further support the study. The goal for collecting documents was to determine which elements of delivery and accountability are outlined in each districts mentor program guidelines.

Directly following the initial survey responses, the researchers sent an additional survey to mentor teachers who had mentored at least one mentee between the 2013-2014 and 2016-2017 school years. Both the mentor leader survey and the mentor teacher survey contained questions which are quantitative and qualitative in nature. Mentor teachers who participated in the study also had the opportunity to participate in a focus group interviews at each district site. The interviews probed for information regarding 
the delivery and monitoring of the mentoring programs in each district participating in the study. Merriam (2009) noted the importance of purposeful sampling to include people who are knowledgeable about the topic and encouraged groups which include six to ten participants. For this study, groups of six to eight participants was the goal for collecting qualitative data.

\section{Data Collection Tools}

Data collection for the study was obtained through the analysis of two sets of survey responses, focus group interviews, and the review of available existing mentor program documents. More specifically, the primary researcher utilized a 15 -question survey composed of close-ended questions with a few open-ended questions to gather information from the program leaders. The survey began with questions which were easiest and most comfortable for participants to answer and continued with questions which were more subjective in style as suggested by Fink (2013). Following the initial survey of mentor leaders, mentor teachers from each district were contacted for participation in the study. The interested mentor teachers received an online consent and an electronic survey consisting of 12 questions, both quantitative and qualitative in nature.

Additionally, qualitative data was collected utilizing focus group interviews of mentor teachers. The goal of the focus group interview questions was to gain insights about both research questions from mentor teachers themselves. Interviews were conducted at individual sites to allow for minimal travel for participants and were approximately forty-five minutes in length. The primary researcher participated in note- 
taking during the focus group interviews to collect the data, in addition to tape recording the interviews.

\section{Data Analysis}

Both quantitative and qualitative data was collected and available for analysis in the study. For the quantitative data portion of this study, the data collected from the closed-ended questions about the elements of mentoring program delivery and accountability present in the selected districts was analyzed and displayed in various graphs and tables. For the qualitative data in this study, detailed notes and jottings were collected and analyzed by the primary researcher. During data analysis, the researchers organized survey participants using the following: LS for leader survey responses 1-4 and MS for mentor surveys 1-54.

Merriam (2009) also suggested "verbatim transcription of recorded interviews provides the best database for analysis" which the researchers utilized (p. 110). From the focus group transcriptions, the primary researcher coded the data throughout the process and identified common threads and emerging themes across districts participating in the study, which was then checked by co-researchers. It was critical to "extend analysis to developing categories, themes, or other taxonomic classes that interpret the meaning of the data" (Merriam, 2009, p. 193) and move towards findings which provided support for the research questions guiding the study. Focus group participants were also organized using FG1, FG2, and FG3 in addition to 1-6 depending on the size of the group. During data analysis, the researcher also reviewed the existing documents to gain key insights into the mentoring programs in addition to the surveys and interviews, noting documents specific to district A, B, and C. 


\section{Findings}

\section{Contact Time}

According to the mentor program leader survey responses, three of the responses indicated weekly contact time is allowed for mentor and mentees, while one response indicated monthly contact time. "Mentors have contact time at least twice a month with each of their new teachers for either an observation or conversation. One formal coaching cycle (with a planning conversation, an observation, and a reflective conversation) per year" (LS1). In the mentor teacher survey, mentors had similar responses about the contact time allowed between mentors and mentees (see Figure 1).

\section{<Insert Figure 1 here>}

The study also found weekly contact time between mentors and mentees was the most common frequency for interactions $(77 \%)$ and monthly contact time was the next most common (13\%). During focus group interviews and analysis of mentor handbooks, the researcher learned a variety of expectations for contact time across the three districts beyond weekly or monthly expectations. District $\mathrm{C}$ begins contact time with mentees through an Academy setting with at least three days of professional development for all first and second year teachers. District A begins contact time with a Mentor and Mentee luncheon at the beginning of the school year during New Teacher Week. During that time, the mentors and mentees receive the district mentoring handbook and guidelines for fulfilling the roles and responsibilities outlined for the year. The handbook states the expectation that mentors and mentees should meet monthly or more often as needed and attend quarterly mentor/mentee sessions. These contact times should be documented 
using the district mentor log and the checklists contain suggested topics to cover during interactions together.

In regards to contact time, specific examples were shared by focus group participants such as “formal sit downs at least monthly, but there's questions to answer all the time too" (FG2-4). Additionally, "As a mentor to your mentee, you are to $\log 12$ contact hours throughout the year and as a $2^{\text {nd }}$ year $\log 6$ hours. It [contact time] can be formal or informal through email or text" (FG3-2). The importance of time to debrief and reflection through conversations with mentees as an important aspect of contact time was noted by FG2-6. Three after school trainings, as well as an opportunity for the mentor, mentee and principals to do a walkthrough together to begin contact time together was also mentioned by a participant (FG1-1).

Additional data collected focused on contact time showed concerns from mentor teacher survey responses regarding when and how the expectations for contact is completed. "All of my mentor time is done on my plan time, or before and after school" (MS22). Another participant noted, "The program is always best when the two teachers work at the same building. It is hard to make schedules work when you are trying to cross over buildings and grade levels" (MS1). Similarly, "Contact time is limited due to schedules and daily demands of the job. The only way I was able to observe my mentee teacher was because I had a student teacher at the time" (MS17). While The New Teacher Center acknowledges requirements in the school day could cause concerns for contact time between mentors and mentees, it is important for districts to have clear expectations for providing weekly or monthly contact opportunities and to provide guidelines for fulfilling those expectations. It should also be noted that District B has two 
full-release mentors in part-time positions and numerous DSS positions providing mentor supports while District A and C have teachers and coaches fulfilling the mentoring roles on top of teaching responsibilities.

\section{Formative Assessment}

Another focus of the research was on the frequency in which mentor and mentees discuss formative assessment. According to the mentor program leader survey responses, three of the responses indicated mentors discuss formative assessments with their mentee once a quarter, while one response indicated monthly discussions. Further, "Formative assessments are discussed as needed, but there is no specific guideline" (LS1) and “clarity regarding formative assessments [is] not spelled out...[in the handbook]" (LS4). In the mentor teacher survey, mentors had a range of responses about the frequency in which mentors and mentees discussed formative assessments (see Figure 2). <Insert Figure 2 here>

Weekly discussions about formative assessments were found to be the most common frequency for interactions $(35 \%)$ and monthly discussions about formative assessments was the next most common (32\%). An additional $24 \%$ of participants indicated once a quarter as the frequency in which formative assessments are discussed and $9 \%$ indicated formative assessments are never discussed between the mentor and mentee. Further, during focus group interviews, FG3-1 and FG3-3 both shared their coaching role with new teachers provides opportunities for a focus on formative assessments, however, neither shared there was a mentoring expectation for discussing formative assessments with their mentees. "In my role [coaching role], that's what I do all day every day...it's how we build on instruction. As a teacher mentor though, the 
early out PLC time is when we have these casual conversations about practices and formative assessments" (FG3-3). Similarly, "In my lit coach position, we use our team meetings to discuss [formative assessments] and we are growing with that in becoming more formulated each quarter" (FG3-1).

In regards to discussing formative assessments with their mentee, one participant shared, "I was not being specific enough- I needed to help my mentee write ideas for using formative assessment checks into her lesson plans...I think it helped a little bit more than me telling her to try this and this and this" (FG2-1). Similarly, another participant noted formative assessments can be "very vague, so sometimes I help set those up- what they look like and 2-3 different ways how they could use them" (FG2-5). Further, participants in focus group one shared that although the district curriculum has become heavy with formative assessments, the mentor role does not include a structure or clear role to talk about formative assessments. However, both high school level mentor teachers in the focus groups indicated a greater focus on mentoring through conversations about formative assessments with their mentees.

Overall, having collaborative conversations about formative assessments was identified by mentor teacher participants as a way to learn what ideas new teachers are bringing with them to the profession and a way to share ideas across teams of veteran and new teachers alike. A goal of including formative assessments into mentoring conversations would be to support mentees in ways to analyze data and plan for the next steps of instruction. Both PLC times and coaching supports for discussing formative assessments surfaced throughout the responses for mentor surveys and focus group responses as a primary mode for supporting new teachers with those discussions. 


\section{Classroom Observation}

A third component of the first research question guiding this study was focused on the frequency in which mentor teachers observed the assigned mentee. According to the mentor program leader survey responses, two of the responses indicated mentors observe mentees on a monthly basis, while the other two responses indicated observations occurred once a semester. LS3 and LS4 both indicated the mentor program handbook provided clear expectations for observations, however the mentor teacher surveys indicated a range of responses about the frequency in which mentors observed their mentee during instruction (see Figure 3).

<Insert Figure 3 here>

The study found $37 \%$ of mentors reported they never observe the mentee during instruction. An additional $22 \%$ of participants indicated once a semester as the frequency in which observations occur and $17 \%$ indicated once a quarter. Once a year observations were reported as the frequency for $13 \%$ of the participants, with the remaining $11 \%$ being either weekly or monthly observations. One participant shared, "I was not provided any time to observe my new teacher" (MS46). Similarly, another noted, "I was disappointed that I was not able to observe my mentee. I think it would have been very helpful for us both" (MS53). In response to the expectation for observing mentees, a respondent shared, "Observation was hard as I am teaching the same times my mentee was teaching proving difficult for me to get into the classroom to observe her" (MS10).

During focus group interviews, one participant noted the following about their role observing new teachers: "My observations are awesome because I have a template that I have created for myself and because I am non-evaluative, I'm still a buddy, a go- 
between, liaison, and still trusted, my observations are when teachers call me in. I also set up a schedule for teachers to observe each other. We do have a template in our handbook for logging hours spent with our teachers but not an observation form" (FG33). From a different standpoint, a respondent noted, "As a mentor program we don't have anything like that [observation form]... it is something we should create if it isn't too binding" (FG3-2). Similarly, another participant indicated a flexible mentoring style for observations which included both scheduled and pop-in observations without the use of specific form (FG1-2).

Additionally, one participant noted, "I have not done that [observation of mentee]...been modeling and partnering alongside but have been spending time building rapport" (FG3-1). Further, the same participant shared district collected surveys provide mentor leaders with information about how the mentoring supports are progressing throughout the year. In one survey response, this participant mentioned the majority of mentoring supports, such as observations, were not coming from an assigned mentor but rather someone else the new teacher had built a connection with.

Another aspect noted by focus group participants was the need to make it clear that the mentor observations are not an evaluation and are not meant to be "stressful or threatening." Further, FG2-6 shared that providing options for how the observations are completed once trust has been build can be beneficial to meeting the observation expectations. An example of how mentor teacher reported being able to complete the observation expectations included a sub provided for the mentee to spend the day with the mentor alongside a coach for debriefing and reflection. District $\mathrm{C}$ also provides the following handbook guidelines: "The building administrator should provide several 
opportunities for the mentor to visit the beginning teacher's classroom during instructional times to complete the observation/feedback cycle. Allowing mentors to observe mentees will improve the systematic approach to developing and retaining highly qualified staff."

When mentor teachers responded to the guidelines for all three components of contact time, formative assessment, and observation in an open-ended question, a variety of responses across the participants were received. A common response included expectations being provided in a handbook or binder or meeting for contact time and observations. More specific responses included "Contact time is necessary, I met daily and observations were expected quarterly in our handbook" (MS6) and "We were emailed a booklet of talking points for each month, but I felt most of them didn't apply to the role my mentee and I serve" (MS4). A similar concern from another mentor teacher included, "There are required activities and checklists that mentor and mentee must complete...I feel that other than the one hour PD and a binder of information that teachers have little time to read there is not a lot of accountability until assignments are due at the end of the year" (MS29).

Overall, the researcher was able to address the first research question, "To what extent are elements of mentor program delivery (contact time, formative assessment, and classroom observation) present in school districts across Southwest Missouri? ” using data collected in the study. The school districts studied in Southwest Missouri identified weekly contact time as the most common frequency for interactions between mentors and mentees. In addition, weekly discussions about formative assessments were the most common, however more discussion about the logistics for supporting formative 
assessment discussions is needed. Finally, the study indicated classroom observations were most likely to occur once a semester or not at all.

\section{Monitoring of Mentor Programs}

The researchers were also interested in the monitoring of mentor programs across the three districts. According to the mentor program leader survey responses, one participant noted "Throughout the year, new teachers are asked about what is beneficial to them...Mentors discuss with each other what is going well or not. An end of year reflective conversation is had with new teachers including an evaluation of the program" (LS1). Additionally, another leader shared "We use checklists for all new hires, mentors, and DSS to complete..." (LS2) and surveys or evaluations are used to "monitor and adjust" mentor program supports according to LS4.

Mentor teacher survey responses showed, "In the handbook given to both the Mentor/Mentee, a clearly defined monthly check-off list is included with certain tasks to do together" (MS5). In regards to their mentor program being monitored, one participant indicated, "Not at all, other than turning in my checklist at the end of the year" (MS11). Similarly, another response shared "District office provides scope and sequence of expected time and topics to be covered. I do not know how this data is used once it's returned to district at the end of the year" (MS16) and another noted, "We have used surveys in the past. I am hoping we start doing interviews to see how well the program is appreciated with our new teachers" (MS20). In a review of District A's handbook, guidance in the form of checklists included a before school checklist, a teacher workshop week checklist, first day checklist, monthly checklists, and observation checklists. These checklists guide mentors to discuss topics such as procedures, parent communication, 
building relationships, curriculum, student discipline, and more. Additionally, District A's mentoring handbook indicates both a Mentee Exit Survey and Mentor Exit Questionnaire is part of the yearly monitoring of mentoring.

During focus group interviews, one participant mentioned, "I've seen a progression to a much more monitored and more intentional approach to our mentoring system. I think we still have some bridges to cross, but we are much more intentional...what we are doing in our new teacher academies is a good example of that" (FG3-3). Two additional responses focused on the monitoring of mentoring through principal check-ins, email reminders, and collected notes by the principal (FG2-1 and FG2-4). Beyond monitoring examples by principals, another respondent indicated the mentor program leader meets monthly with mentees to check on how visits with mentees are going and to address any issues or provided any needed resources the mentors may need (FG1-2). The majority of focus group respondents indicated the monitoring of mentoring as an area needing improvement. Specifically, FG2-2 noted an idea for coming together "mid-year as a mentoring group to support or encourage each other."

Overall, the researcher was able to address the second research question, "How are mentoring programs monitored across school districts in Southwest Missouri?" using data collected in the study. The school districts studied in Southwest Missouri identified checklists, surveys, and evaluations as methods for monitoring mentor programs. In addition, some sites identified principal check-ins and program leader meetings as methods for monitoring. The majority of focus group respondents also indicated monitoring of mentoring programs as an area needing improvement.

\section{Discussion and Limitations}


Guidelines for classroom observations conducted by mentor teachers are outlined for all three districts in this study; however supports and training for observations are lacking consistency. While program leaders identified monthly or semester observations with observation logs, mentor teacher responses showed a large amount of mentors never conducting classroom observations or recording notes from the observation. Focus group participants also had a variety of coverage options or forms used for observations, but indicated a need for more guidance in this area. The researchers identified that each of the school districts could improve observation practices between mentors and mentees by targeting classroom observations as an area of needed improvement.

With the recommendation from The New Teacher Center (2012) to provide cycles of observations that allow for reflection and analysis of the data, districts could provide focused training on these aspects. The districts could gather data about current forms and reflection tools used by mentor teachers to gain information about what tools are working. Districts could also identify options for conducting classroom observations, which offer choice and coverage for the teachers involved. If districts could identify the "how" and "why" and articulate the importance of mentor observations to mentors and mentees, the first step of collecting observation data could increase in a more systematic manner in each district. Additional professional development for mentor teachers from administrators, coaches, or program leaders could be utilized to dive into the analysis of the observation data once cycles of reflection have begun. A study by Odell (2006) confirmed support from leaders as an important element in developing mentors and noted the need for leaders to help collect on-going data to inform mentoring decisions. 
Mentor teachers in both surveys and focus group interviews indicated that increased monitoring of mentor programs could be beneficial to improving mentor practices. Mentor teachers identified checklists, surveys, or leaders who occasionally monitored mentoring as the main method for gathering feedback about mentoring supports in each district. Similarly, research by Ganser (2005) noted end of the year surveys as a typical method for monitoring program satisfaction. However, mentor survey respondents struggled to provide opportunities where monitoring supported them in growing as a mentor teacher. Mentors indicated support sessions or on-going training based on topics of interest or concern as a measure to monitor progress throughout the year could be beneficial. This would provide support throughout the process rather than turning in a log or survey at the end and then reactively making changes for the following year.

There are a number of limitations that readers should consider regarding this study. The primary limitation is the sample size as the study was conducted in a small portion of one state, which could limit transferability. In addition, the researchers did not identify ethnicity or gender of participants in either of the surveys, though the districts are known to consist of over $90 \%$ white teachers. The focus groups were comprised of white females and one white male. The overall sample size across the surveys and focus groups consisted of 70 total participants, with a large majority of mentors fulfilling roles in elementary settings.

Overall, data collected related to the elements of contact time, formative assessment, and classroom observation provided further information as it related to The New Teacher Center's criterion seven review of Missouri. While weekly contact time 
between mentors and mentees was found to be the most common frequency for interactions, The New Teacher Center's recommendation for weekly protected-time between 1.25 and 2.5 hours for mentor and mentee interactions leaves more to be studied. In addition, the concerns related to contact time included when and how the expectations for contact time are completed. Similarly, while weekly discussions about formative assessments were the most common frequency for interactions, The New Teacher Center recommends increasing these discussions to further impact individual teacher performance. Additionally, in order to support more formative assessment discussions, mentors indicated a need to know when and who to include in learning around formative assessments. 
Figure 1:

\section{Mentor Contact Time with Mentees}

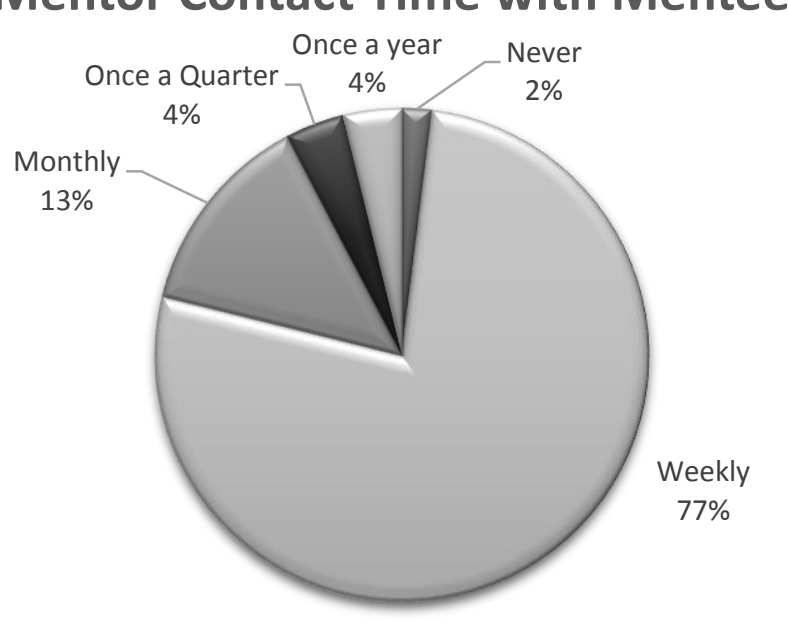

Figure 2:

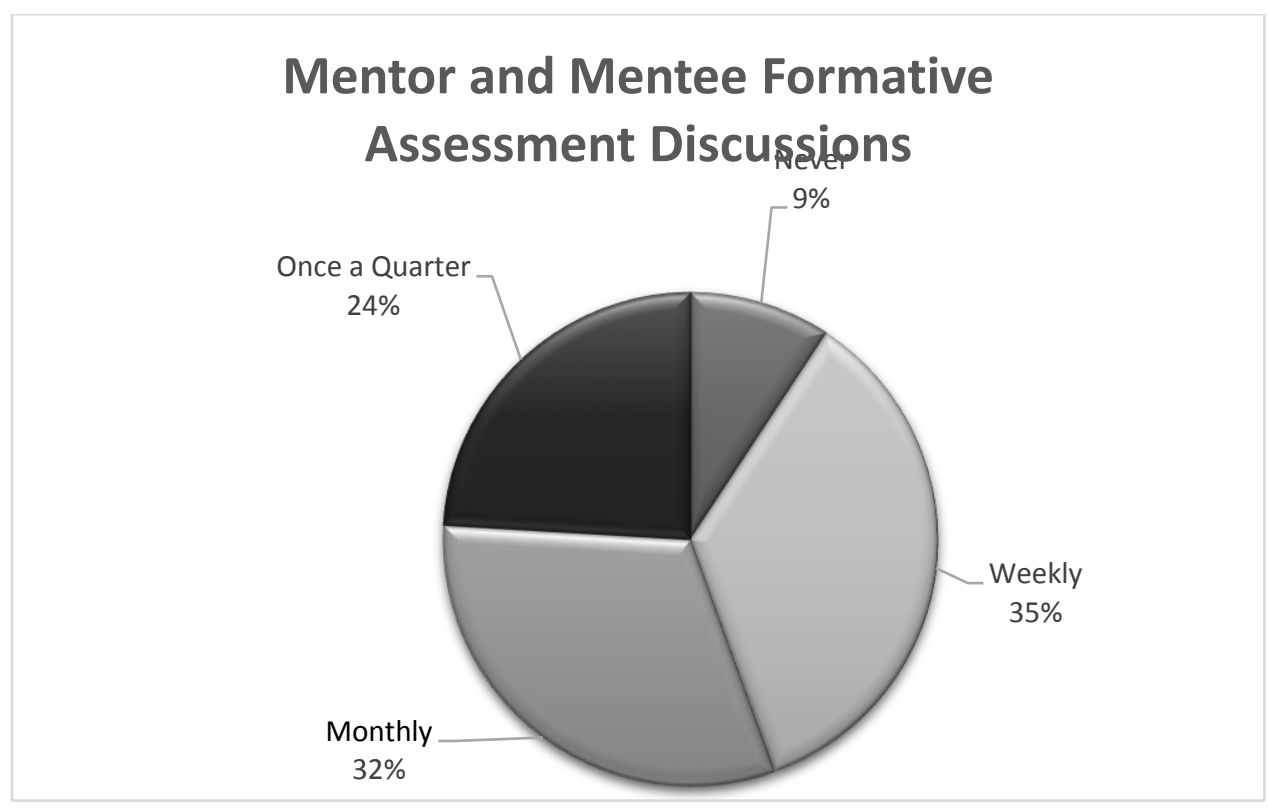


Figure 3:

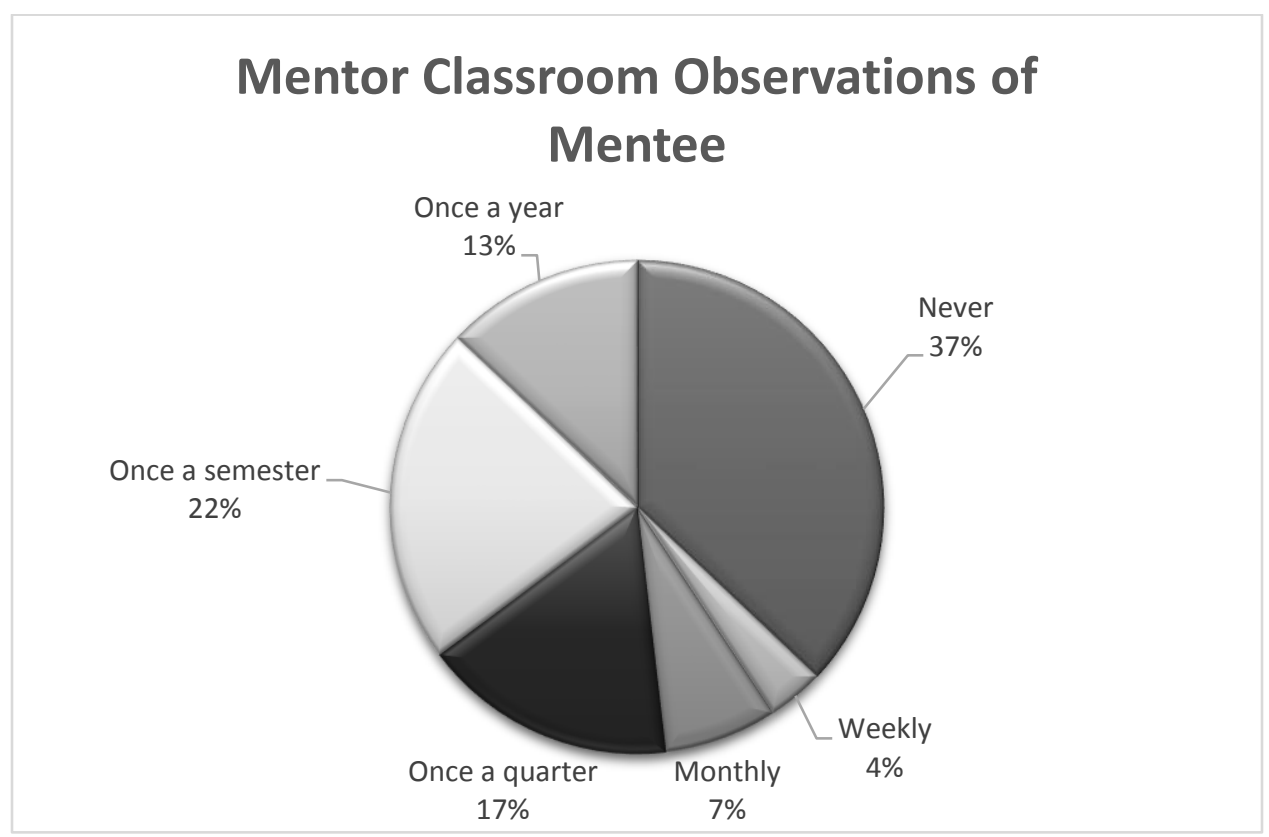




\section{References}

Athanases, S. Z., Abrams, J., Jack, G., Johnson, V., Kwock, S., McCurdy, J., Riley, S., \& Totaro, S. (2008), "Curriculum for mentor development: problems and promise in the work of new teacher induction leaders", Journal of Curriculum Studies, Vol. 40 No. 6, pp. 743-770.

Borko, H. (1986). Clinical teacher education: The induction years. In J. V. Hoffman and S. A. Edwards, Reality and reform in clinical teacher education (pp. 42-52). New York, NY: Random House.

Casey, J., \& Claunch, A. (2005). The stages of mentor development. In Teacher mentoring and induction (pp. 95-108), Thousand Oaks, CA: Corwin Press.

Creswell, J. H. (2014), Research design: Qualitative, quantitative, and mixed methods Approaches, Sage, Thousand Oaks, CA.

Feiman-Nemser, S. (2012). Beyond solo teaching. Educational Leadership, 69(8), 10-16.

Fink, A. (2013), How to conduct surveys: A step-by-step guide (5th ed.), Sage, Thousand

Oaks, CA.

Galvez-Hjornevik, C. (1986), "Mentoring among teachers: A review of the literature”, Journal of Teacher Education, Vol. 37 No. 1, pp. 6-11.

Ganser, T. (2005). Learning from the past- Building for the future. In Teacher mentoring and induction (pp. 3-19), Thousand Oaks, CA: Corwin Press.

George, B., Sims, P., McLean, A. N., \& Mayer, D. (2011). Discovering your authentic leadership. In HBR's 10 must reads on leadership (pp. 163-177), Boston, MA: 
Harvard Business Review Press. (Reprint R0702H, Originally published in February 2007)

Goldrick, L., Osta, D., Barlin, D., \& Burn, J. (2012). Review of state policies on teacher induction. Santa Cruz, CA: New Teacher Center.

Ingersoll, R. (2002). The teacher shortage: A case of wrong diagnosis and wrong prescription. NASSP Bulletin, 86, 631.

Ingersoll, R. (2012). Beginning teacher induction: What the data tell us. Education Week, Phi Delta Kappan.

Levinson, D. (1978), The seasons of a man's life, Knopf, New York, NY.

Lieberman, A., Hanson, S., \& Gless, J. (2012), Mentoring teachers: Navigating the realworld tensions, Jossey-Bass, San Francisco, CA.

Merriam, S. B. (2009), Qualitative research: A guide to design and implementation (3rd ed.), Jossey-Bass, San Francisco, CA.

New Teacher Center. (2012). Review of state policies on teacher induction. Retrieved from http://www.newteachercenter.org/sites/default/files/ntc/main/resources/brfntc-policy-state-teacher-induction.pdf

Waterman, S. \& He, Y. (2011). Effects of mentoring programs on new teacher retention: A literature review. Mentoring \& Tutoring: Partnership in Learning, 19(2), 139156. 
SECTION SIX:

SCHOLARLY PRACTIONER REFLECTION 


\section{Scholarly Reflection}

There has never been a doubt that education and life-long learning would be one of the most prominent components of my life. This realization strengthened during my career as a public educator when I had the privilege of learning and growing alongside thousands of students and hundreds of teachers. At the start of my educational career, however, I began as a new teacher without a year-long assigned mentor. I quickly recognized how difficult it was to rely on team members for support with my beginning teacher needs and as a result, the first two years became a quest for survival with observations by the principal and advice from teammates as the primary mode for feedback about my instruction. After switching into an instructional coach role a few years into my career, I was surprisingly assigned to be a mentor to new teachers. Even though I was aware that my lack of experience with mentoring would make this new role a challenge, I was eager to immerse myself in learning about mentoring.

My learning about mentoring began by studying Educational Leadership articles in the Supporting Beginning Teachers issue and attending a district mentor training meeting. The articles and training experience sparked a realization of how critical mentor supports could be for beginning teachers and also mirrored what I was experiencing as a first year mentor teacher. My experiences in the role as a mentor were similar to Lieberman, Hanson, and Gless' (2012) description of mentoring which included engaging in discussion and providing resources for my mentees as well as conducting observations of instruction. I struggled to find a balance between providing more of a buddy support system focused on management or issues my mentees were facing versus an instructional support system focused on feedback from observations. As I reflected on the mentoring 
experiences, I recognized my minimal training for the role was both detrimental but a catalyst for further discovery as a learner.

After my initial experiences with mentoring, I made a decision to take my learning further with a dissertation focused on mentoring. While diving deeper into my learning about mentoring, I found the literature review process to be a powerful opportunity for understanding the complexities of mentoring. A literature review by Waterman and He (2011) suggested the need for studying mentoring through more than just quantitative study, and Creswell's (2014) description of a convergent parallel design provided the avenue for a mixed methods study. Additional studies on mentoring combined with The New Teacher Center's (2012) review of mentoring across the states helped guide me to a focus on program delivery and accountability. This focus provided the lens for the research questions and multiple data collection tools allowed for an additional focus on mentor training and perceptions. Further, I was able to utilize my learning from the two years of coursework as a foundation for engaging in the scholarly writing process as I became more immersed in the dissertation process.

Overall, the combination of reading, discussing, and writing throughout the dissertation process created a successful layering of learning for me. During the revision process of my literature review, I discovered studies in other states and countries, which helped me confirm the need for additional studies on mentoring. Further, through discussion with my advisor and committee, I was encouraged to emphasize a focus on contact time, formative assessments, classroom observations, and monitoring which provided an additional lens for diving deeper into my study. Additional feedback from my committee about the survey tools was also paramount in my successful use of data 
collection tools. These experiences early into the dissertation process confirmed for me that I was on the right track to having a meaningful study, which would impact me as a scholar.

During the data collection phase of the dissertation, I became increasingly aware of both the challenges and rewards of studying more than one district. The opportunity to research beyond my district of employment offered an eye-opening experience as it was both difficult gaining permission to study multiple districts, but also provided three different views of mentoring programs. Throughout the process, I was able to expand my network to include mentors and program leaders in two additional districts, which became one of the most rewarding parts of this experience. Further, I became determined to collect data from as many program leaders and mentor teachers from the three participating districts as possible and to analyze that data with integrity. In addition, focus group participants offered feedback on my knowledge based around mentoring and my self-confidence increased throughout this phase of the dissertation.

Surprisingly, the most difficult part of the dissertation process did not surface for me until I reached the journal submission stage. In the beginning, a primary reason for selecting the University of Missouri doctoral program was the focus on a submission ready piece to contribute to practice. During this phase of the dissertation, however, I realized just how focused, organized, and determined I needed to be as I endured writing drafts for multiple journals. The confidence I had gained from the proposal and data collection phases had faded away, and I felt like I was crawling to the finish line unsuccessfully. Thankfully, my passion for the topic of mentoring, inspiring articles 
from the International Journal of Mentoring and Coaching in Education, and my desire to complete my dissertation by mid thirty all kicked in to help me complete the task.

\section{Leadership Reflection}

In the beginning of my career, my experiences in the classroom offered new challenges and opportunities to grow on a daily basis, but a true leadership role was lacking. While I recognized opportunities for leading during team meetings, professional development sessions, and interactions with coaches, I also realized my strong desire for engaging in discussions with my adult peers and instructional leaders. At that point, I realized I needed to glean as much as possible from the leaders around me and develop my strengths and weaknesses as a leader. This quest for development is what compelled me to continue my education through the University of Missouri's Educational Leadership and Policy Analysis program. I believe I have had the opportunity to transform my leadership throughout the program and dissertation process.

As I reflect on how the doctoral journey as a whole has influenced me as a leader, I am reminded of Goleman's (1996/2011) description of leaders as people who demonstrate the fundamental aspects of optimism and organizational commitment while being motivated to achieve. Part of my reasoning for joining the doctoral program at the University of Missouri was the cohort setting, which sounded like a perfect fit for a motivated learner and an opportunity to grow my professional network. I was committed to engaging with cohort peers through the various research projects and conversations about organizations and educational policies. With each passing week of classes and summer learning experiences, I layered on my learning from the other leaders in the program and began to develop more leadership skills along the way. 
During the program, I also confirmed how fortunate I have been to experience various types of leadership through my relationships with principals and district leaders in my school settings. The doctoral program provided an opportunity to reflect on the impact of those leaders and to remember why I embarked on my further studies. One leader in particular provided me with experiences described by Kotter (1990/2011) as "opportunities during their twenties and thirties to actually try to lead, to take a risk, and to learn from both triumphs and failures" (p. 53). I took my first major risk when I started my instructional coaching journey and my second when I began my doctoral journey. During both situations, I had the support of a transformational leader who influenced me to accomplish more than even I expected for myself. She modeled both inspirational motivation and intellectual stimulation in a way that propelled me to want to grow as a leader (Northouse, 2013).

While the majority of my coaching relationships and doctoral experiences have been successful, there have been some difficulties and bumps along the way. One of the greatest difficulties was taking on Reading Recovery training during my first year of coaching and doctoral studies as part of my new position in Ozark Schools. This training required additional reading and an intense focus on applying my learning as I served six students throughout the year. At times, required readings and data collection for both the Reading Recovery training and doctoral studies overlapped and became a competing focus for me. On the other hand, I had the opportunity to learn from an exceptional Reading Recovery leader and practiced collecting survey data using a Reading Recovery focus. In addition to a successful completion of my Reading Recovery training, I also built coaching relationships with teachers, fellow coaches, and district leaders throughout 
my first year in Ozark. Many of these individuals as well as my cohort peers have continued to engage in conversations with me about my doctoral learning, especially my study on mentoring. Although it was difficult to leave my support system in Nebraska schools and to transfer my learning from past experiences to my new surroundings, it has opened many doors for new learning. In the end, both the successes and difficulties have been opportunities for reflection and growth for me during my leadership journey thus far.

Although my transformation as a leader began when I started my coaching role, I believe the greatest influences on my leadership began when I took on a new leadership role as a result of the cohort discussions during summer two regarding policy. This new leadership position would become a way to become more involved in my district and state and would impact my desire to research beyond just one district. I was also able to gain leadership insight by attending board meetings, collective bargaining conversations, and regional and state conversations around policy as a result of this new role. Further, the role pushed me out of my comfort zone, offered new learning, and provided an additional network of leaders for me to connect with. I have continued to gain selfconfidence, accomplish new tasks, and successfully add another layer to my supports for adult learners through this role. Similar gains in my dissertation process were made possible because of this leadership opportunity.

My transformation as a leader throughout the dissertation process can also be evidenced through my interactions with peers. Merriam's (2014) description of adults wanting to be able to connect and apply what they are learning to their own settings has been both relevant and critical to remember in my interactions. As a leader of team 
meetings and professional development sessions for my district, I have had the opportunity to guide teams of teachers in the processes of reading, writing, and discussing to deepen knowledge about certain topics. I have also embarked on mini research studies with new teachers to discover areas of strength and needed growth for instructional strategies used with students. Additionally, I continue to be eager to apply more of my learning about adult learners, specifically around mentoring, now that I have participated in this research process. Moving forward, I am interested in taking on a leadership role in my district's mentoring program following the completion of program. I think the leadership skills I have gained in addition to the scholarly learning will make me a valuable support in my district. 


\section{References}

Athanases, S. Z., Abrams, J., Jack, G., Johnson, V., Kwock, S., McCurdy, J., Riley, S., \& Totaro, S. (2008). Curriculum for mentor development: problems and promise in the work of new teacher induction leaders. Journal of Curriculum Studies, 40(6), 743770.

Beutel, D., Crosswell, L., Willis, J., Spooner-Lane, R., Curtis, E., \& Churchward, P. (2017). Preparing teachers to mentor beginning teachers: an Australian case study. International Journal of Mentoring and Coaching in Education, 6(3), 164-177.

Bieler, D. (2012). What new teachers want from colleagues. Educational Leadership, 69(8), 4649.

Bolman, L. G., \& Deal, T. E. (2008). Reframing organizations: Artistry, choice and leadership (4th ed.). San Francisco, CA: Jossey-Bass.

Borko, H. (1986). Clinical teacher education: The induction years. In J. V. Hoffman and S. A. Edwards, Reality and reform in clinical teacher education (pp. 42-52). New York, NY: Random House.

Bullough, R. V., Jr., (2005). Being and becoming a mentor: School-based teacher educators and teacher educator identity. Teaching \& Teacher Education, 21(2), 143-155.

Casey, J., \& Claunch, A. (2005). The stages of mentor development. In Teacher mentoring and induction (pp. 95-108), Thousand Oaks, CA: Corwin Press.

Creswell, J. H. (2014). Research design: Qualitative, quantitative, and mixed methods approaches. Thousand Oaks, CA: Sage.

Daloz, L. A. (1999). Mentor: Guiding the journey of adult learners. San Francisco, CA: Jossey-Bass. 
Danielson, C. (1999). Mentoring beginning teachers: The case for mentoring. Teaching and Change, 6(3), 251-257.

Darling-Hammond, L. (2003). Keeping good teachers: Why it matters, what leaders can do. Educational Leadership, 60(8), 6-13.

Drake, P., \& Heath, L. (2011). Practitioner research at doctoral level: Developing coherent research methodologies. New York, NY: Routledge.

Evertson, C. M., \& Smithey, M.W. (2000). Mentoring effects on protégés classroom practice: An experimental field study. Journal of Educational Research, 93(5), 294-304.

Feiman-Nemser, S. (2001). Helping novices learn to teach: Lessons from an exemplary support teacher. Journal of Teacher Education, 52(1), 17-30.

Feiman-Nemser, S. (2012). Beyond solo teaching. Educational Leadership, 69(8), 10-16.

Fideler, E., \& Haselkorn, D. (1999). Learning the ropes: Urban teacher induction programs and practices in the United States. Belmont, MA: Recruiting New Teachers.

Fink, A. (2013). How to conduct surveys: A step-by-step guide (5th ed.). Thousand Oaks, CA: Sage.

Fuller, F. (1969). Concerns of teachers: A developmental conceptualization. American Educational Research Journal, 6(2), 207-226.

Galvez-Hjornevik, C. (1986). Mentoring among teachers: A review of the literature. Journal of Teacher Education, 37(1), 6-11.

Ganser, T. (2001). Building the capacity of school districts to design, implement, and evaluate new teacher mentor programs. ERIC Document Reproduction No. ED 452169 , Springfield, VA. 
Ganser, T. (2005). Learning from the past- Building for the future. In Teacher mentoring and induction (pp. 3-19), Thousand Oaks, CA: Corwin Press.

George, B., Sims, P., McLean, A. N., \& Mayer, D. (2011). Discovering your authentic leadership. In HBR's 10 must reads on leadership (pp. 163-177), Boston, MA: Harvard Business Review Press. (Reprint R0702H, Originally published in February 2007)

Gill, S. J. (2010). Developing a learning culture in nonprofit organizations. Los Angeles, CA: Sage.

Gold, Y. (1999). Beginning teacher support. In J. Sikula, T. Buttery, \& E. Guyton (Eds.), Handbook of research in teacher education (2nd ed.) (pp. 548-594). New York, NY; Macmillan.

Goldrick, L., Osta, D., Barlin, D., \& Burn, J. (2012). Review of state policies on teacher induction. Santa Cruz, CA: New Teacher Center.

Goleman, D. (2011). What makes a leader? In HBR's 10 must reads on leadership (pp. 121), Boston, MA: Harvard Business Review Press. (Reprint R0401H, Originally published in June 1996)

Grossman, P., \& Davis, E. (2012). Mentoring that fits. Educational Leadership, 69(8). 54-57.

Haggarty, L., Postlethwaite, K., Diment, K., \& Ellins, J. (2011). Improving the learning of newly qualified teachers in the induction year. British Educational Research Journal, 37(6), 935-954.

Hall, J. (2005). Promoting quality programs through state-school relationships. In Teacher mentoring and induction (pp. 213-223), Thousand Oaks, CA: Corwin Press. 
Hobson, A. J., Ashby, P., Malderez, A., \& Tomlinson, P. D. (2009). Mentoring beginning teachers: What we know and what we don't. Teaching \& Teacher Education, 25(1), 207 216.

Huling, L., \& Resta, V. (2007). CREATE teacher induction study: The relationship of mentor support to novice teacher retention and student achievement: Phase II report. Woodlands, TX: Center for Research, Evaluation, and Advancement of Teacher Education.

Ingersoll, R. (2002). The teacher shortage: A case of wrong diagnosis and wrong prescription. NASSP Bulletin, 86, 631.

Ingersoll, R. (2012). Beginning teacher induction: What the data tell us. Education Week, Phi Delta Kappan.

Ingersoll, R., \& Kralik, J. (2004). The impact of mentoring on teacher retention: What the research says. Education Commission of the States Report. Document Number: 5036.

Johnson, W.B., \& Ridley, C.R. (2008). The elements of mentoring. New York, NY: Palgrave Macmillan.

Kalin, N., Barney, D., \& Irwin, R. (2010). Complexity thinking mentorship: An emergent pedagogy of graduate research development. Mentoring and Tutoring: Partnership in Learning, 17(3), 353-367.

Kotter, J. (2011). What leaders really do. In HBR's 10 must reads on leadership (pp. 3755), Boston, MA: Harvard Business Review Press. (Reprint R0111F, Originally published in May 1990) 
Kram, K. (1983). Phases of the mentoring relationship. Academy of Management Journal, 26, 608-625.

Levi, D. J. (2014). Group dynamics for teams (4th ed.). Los Angeles, CA: Sage.

Levinson, D. (1978). The seasons of a man's life. New York, NY: Knopf.

Lieberman, A., Hanson, S., \& Gless, J. (2012). Mentoring teachers: Navigating the realworld tensions. San Francisco, CA: Jossey-Bass.

Lipton, L., \& Wellman, B. (2003). Cultivating learning-focused relationships between mentors and their protégés. In Teacher mentoring and induction (pp. 95-108), Thousand Oaks, CA: Corwin Press.

McDavid, J. C., Huse, I., \& Hawthorn, L. R. L. (2013). Program evaluation and performance measurement: An introduction to practice. Thousand Oaks, CA: Sage.

Merriam, S. B. (2009) Qualitative research: A guide to design and implementation (3rd ed.). San Francisco, CA: Jossey-Bass.

Merriam, S. B., \& Bierema, L. L. (2014). Adult learning: Linking theory and practice. San Francisco, CA: Jossey-Bass.

National Center for Research on Teacher Learning. (1993). Findings on learning to teach. East Lansing, MI: National Center for Research on Teacher Learning, College of Education, Michigan State University.

National Commission on Teaching and America's Future (NCTAF). (1996). What matters most: Teaching for America's future. New York, NY. 
New Teacher Center. (2012). Review of state policies on teacher induction. Retrieved from http://www.newteachercenter.org/sites/default/files/ntc/main/resources/brf-ntc-policy state-teacher-induction.pdf

New Teacher Center. (2016). State and local policy. Retrieved from https://newteachercenter.org/policy/

Northouse, P. G. (2013). Leadership: Theory and practice (6th ed.). Los Angeles, CA: Sage.

O’Neil, J. (1981). Toward a theory and practice of mentoring in psychology. In J. H. O’Neil \& L.S. Wrightsman (Eds.), Mentoring: Psychological, person and career implications.

Ormond, C. (2011). Tailoring mentoring for new mathematics and science teachers: An exploratory study. Australian Journal of Teacher Education, 36(4).

Perez, R., \& Ciriza, F. (2005). Making each new teacher our responsibility (MENTOR): End-of-year report. Retrieved from http://eric.ed.gov/ PDFS/ED490615.pdf.

Portner, H. (2005). Teacher mentoring and induction. Thousand Oaks, CA: Corwin Press.

Rath, T. \& Conchie, B. (2008). Strengths based leadership: Great leaders, teams, and why people follow. New York, NY: Gallup Press.

Resta, V. (2006). Overview and framework. In Research on teacher induction: Teacher education yearbook XIV. Lanham, MD: Rowman \& Littlefield Education.

Schien, E. (1978). Career dynamics: Matching individual and organizational needs. Reading, MA: Addison-Wesley.

Simpson, T., Hastings, W., \& Hill, B. (2007). "I knew that she was watching me'”: The 
professional benefits of mentoring. Teachers and Teaching: Theory and Practice, 13(5), 481-498.

Spears, L. C. (2010). Character and servant leadership: Ten characteristics of effective, caring leaders. The Journal of Virtues and Leadership, 1(1), 25-30.

Stanulis, R., \& Ames, K. T. (2009). Learning to mentor: Evidence and observation as tools in learning to teach. Professional Educator, 33(1), 28-38.

Strong, M. (2009). Effective teacher induction and mentoring. New York, NY: Teachers College Press.

Sweeny, B. (2005). Mentoring Time and Timing. In H. Portner (Ed). Teacher mentoring and induction: The state of the art and beyond. (pp. 129-148). Thousand Oaks: CA. Corwin Press.

Vonk, J. H. C. (1993). Mentoring beginning teachers: Development of a knowledge base for mentors. Annual Meeting of the American Educational Research Association, Atlanta.

Waterman, S., \& He, Y. (2011). Effects of mentoring programs on new teacher retention: A literature review. Mentoring \& Tutoring: Partnership in Learning, 19(2), 139156.

Wong, H. (2005). New teacher induction: The foundation for comprehensive, coherent, and sustained professional development. In Teacher mentoring and induction (pp. 41-58), Thousand Oaks, CA: Corwin Press.

Wong, H., Britton, T., \& Ganser, T. (2005). What the world can teach us about new teacher induction. Phi Delta Kappan, 86(5), 379-384. 


\section{Appendix A \\ Informed Consent for Mentor Program Leader Survey}

Research Study's Title: Mentor Program Delivery and Accountability: A Mixed Methods Study in Southwest Missouri

Purpose of this study: This study is a mixed methods study focused on the aspects of program delivery and training as well as the mentor program accountability and monitoring. The researcher hopes to gain information about these elements of mentoring from both mentor program leaders and mentor teachers within several districts in the Southwest region of Missouri. This is a research study to meet the requirements for a University of Missouri doctoral degree.

Participant selection: You are invited to participate in this study because of your role as a mentor program leader in your district. The goal of this study is to gather information from mentor program leaders who are involved in providing training and monitoring for mentors and mentees in their respective district between the 2013 and 2016 school years. Your participation in this research is voluntary, should you decide to participate.

\section{What can you expect during participation?}

If you agree to be in the study, you will be asked to complete a survey which consists of 15 questions, primarily of qualitative nature. Please note your participation is completely voluntary and you can stop answering questions/leave questions blank at any time. You may withdraw or refuse to participate in the research study without any penalty or loss of benefit to which you are otherwise entitled.

\section{Are there benefits or risks for participating in this study?}

There are no intended benefits or risks for participants in this survey. The research aims to benefit the school districts who participate during the dissemination of information phase following the completion of the study.

\section{How will responses be collected and shared?}

Your responses to the survey will be confidential as your name and email addresses will not be linked to the data in the survey. Data will be collected and shared using pseudonyms to protect the participants.

\section{Online consent signature:}

I have read the description above and I understand what is being asked of me as a participant. In lieu of a signed consent form, my participation in the study by answering the survey questions will indicate I have read and understand the informed consent and agree participate in the study. 


\section{Questions:}

If you have questions, please contact Angela Boyer at 402-560-1867 at angelaboyer@mail.ozark.k12.mo.us or Dr. Jeffrey Cornelius-White at 417-836-6517 at jcornelius-white@missouristate.edu. The IRB Contact is 573-882-3181 or irb@missouri.edu. 


\section{Appendix B \\ Survey for Mentor Program Leaders}

For questions 1-5, please share your knowledge about the mentor program at your site.

1. Please report how many years mentoring has been provided for new teachers in your district.

2. Please report how many years new teachers typically receive mentoring in your district's program.

3. Please report (or at least estimate) how many beginning teachers are receiving mentoring support during the 2016-2017 school year in your district.

4. Please report (or at least estimate) how many mentor teachers are receiving mentor training during the 2016-2017 school year in your district.

5. Please report how many teachers have participated in the role of mentor teacher since the 2013-2014 school year in your district.

For questions 6-12, please mark the choice which best matches your current knowledge about the mentor program at your site.

6. About how many hours will be spent providing mentor training to mentors during the 2016-2017 school year in your district?

$\circ \quad 0-5$

○ 6-10

○ $11-15$

○ $16-20$

- 21 or more

7. How frequently are mentors and mentees allowed contact time?
- Never
○ Weekly
○ Monthly
- Once a quarter
- Once a semester
- Once a year 
8. How frequently do mentor and mentees meet to discuss formative assessments?
○ Never
- Weekly
○ Monthly
- Once a quarter
- Once a semester
$\circ$ Once a year

9. How frequently do mentor teachers observe their mentee during instruction?
- Never
○ Weekly
○ Monthly
- Once a quarter
- Once a semester
$\circ$ Once a year

10. To what extent do you agree with the following statement: It would be beneficial for all beginning teachers to receive mentoring from a trained mentor.
- Strongly disagree
○ Disagree
- Slightly disagree
- Slightly agree
○ Agree
○ Strongly agree

11. To what extent do you agree with the following statement: My district has a mentor training program in place that includes training for mentor teachers.
○ Strongly disagree
○ Disagree
- Slightly disagree
$\circ$ Slightly agree
- Agree
○ Strongly agree

12. To what extent do you agree with the following statement: Interviews, surveys, or evaluations are conducted at least yearly to collect information from mentors about their mentoring experiences. 


$$
\begin{array}{ll}
\circ \text { Strongly disagree } \\
\circ \text { Disagree } \\
\circ & \text { Slightly Disagree } \\
\circ & \text { Slightly Agree } \\
\circ & \text { Agree } \\
\circ & \text { Strongly agree }
\end{array}
$$

For questions $13-15$, please share your responses to the open-ended questions using the text boxes provided.

13. Please describe the guidelines for mentor program delivery in regards to contact time, formative assessment, and observations.

14. Please describe how mentor programs are monitored in your district. In what ways are surveys, interviews, or evaluations used?

15. Would you be willing to share a survey with teachers who have participated in the mentor teacher role between 2013 and the current school year?

Please provide any additional information about the mentoring program at your site that you did not get to share in your answers to the questions above.

If you would be willing to provide mentor program documents relevant to your district, please contact me at the following email: aboyer318@gmail.com 


\section{Appendix C \\ Informed Consent for Mentor Teacher Survey}

Research Study's Title: Mentor Program Delivery and Accountability: A Mixed Methods Study in Southwest Missouri

Purpose of this study: This study is a mixed methods study focused on the aspects of program delivery and training as well as the mentor program accountability and monitoring. The researcher hopes to gain information about these elements of mentoring from both mentor program leaders and mentor teachers within several districts in the Southwest region of Missouri. This is a research study to meet the requirements for a University of Missouri doctoral degree.

Participant selection: You are invited to participate in this study because of your role as a mentor teacher in your district. The goal of this study is to gather information from mentor teachers who have supported at least one mentee in their respective district between the 2013 and 2016 school years. Your participation in this research is voluntary, should you decide to participate.

\section{What can you expect during participation?}

If you agree to be in the study, you will be asked to complete a survey which consists of 12 questions, both quantitative and qualitative in nature. Please note your participation is completely voluntary and you can stop answering questions/leave questions blank at any time. You may withdraw or refuse to participate in the research study without any penalty or loss of benefit to which you are otherwise entitled.

\section{Are there benefits or risks for participating in this study?}

There are no intended benefits or risks for participants in this survey. The research aims to benefit the school districts who participate during the dissemination of information phase following the completion of the study.

\section{How will responses be collected and shared?}

Your responses to the survey will be confidential as your name and email addresses will not be linked to the data in the survey. Data will be collected and shared using pseudonyms to protect each participant.

\section{Online consent signature:}

I have read the description of the survey above and I understand what is being asked of me as a participant. In lieu of a signed consent form, my participation in the study by answering the survey questions will indicate I have read and understand the informed consent and agree to participate in the study. 


\section{Questions:}

If you have questions, please contact Angela Boyer at 402-560-1867 at angelaboyer@mail.ozark.k12.mo.us or Dr. Jeffrey Cornelius-White at 417-836-6517 at jcornelius-white@missouristate.edu. The IRB Contact is 573-882-3181 or irb@missouri.edu. 


\section{Appendix D \\ Survey for Mentor Program Teachers}

For questions 1-8, please mark the choice which best matches your current knowledge about the mentor program at your site.

1. How many years have you provided supporting to beginning teachers through your role as a mentor teacher?

○ $1-3$

○ $4-6$

○ $7-9$

○ 10 or more

2. About how many hours of mentor training have you participated in at your current district site?
$\circ \quad 0-10$
○ $11-20$
○ 21-30
- 31 or more

3. How frequently are your allowed contact time with your mentee?
- Never
○ Weekly
○ Monthly
- Once a quarter
- Once a semester
$\circ$ Once a year

4. How frequently do you meet with your mentee to discuss formative assessments?
- Never
○ Weekly
○ Monthly
- Once a quarter
- Once a semester
$\circ$ Once a year

5. How frequently do you observe your mentee during instruction? 
○ Never

○ Weekly

○ Monthly

- Once a quarter

- Once a semester

o Once a year

6. To what extent do you agree with the following statement: It would be beneficial for all beginning teachers to receive mentoring from a trained mentor.

○ Strongly disagree

○ Disagree

- Slightly disagree

- Slightly agree

- Agree

○ Strongly agree

7. To what extent do you agree with the following statement: My district has a mentor training program in place that includes training for mentor teachers.

- Strongly disagree

- Disagree

- Slightly disagree

○ Slightly agree

○ Agree

- Strongly agree

8. To what extent do you agree with the following statement: Interviews, surveys, or evaluations are conducted at least yearly to collect information from mentors about their mentoring experiences.

- Strongly disagree

○ Disagree

○ Slightly Disagree

- Slightly Agree

- Agree

- Strongly agree

For questions 9-12, please share your responses to the open-ended questions using the text boxes provided. 
9. What supports come to mind when you think of mentor teacher training?

10. Please describe the guidelines for mentor program delivery in regards to contact time, formative assessment, and observations.

11. Please describe how mentor programs are monitored in your district. In what ways are surveys, interviews, or evaluations used?

12. Would you be willing to participate in a focus group interview to further discuss your mentor training and monitoring?

Please provide any additional information about the mentoring program at your site that you did not get to share in your answers to the questions above. 


\section{Appendix E \\ Informed Consent for Mentor Teacher Focus Group Interviews}

Research Study's Title: Mentor Program Delivery and Accountability: A Mixed Methods Study in Southwest Missouri

Purpose of this study: This study is a mixed methods study focused on the aspects of program delivery and training as well as the mentor program accountability and monitoring. The researcher hopes to gain information about these elements of mentoring from both mentor program leaders and mentor teachers within several districts in the Southwest region of Missouri. This is a research study to meet the requirements for a University of Missouri doctoral degree.

Participant selection: You are invited to participate in this study because of your role as a mentor teacher in your district. The goal of this study is to gather information from mentor teachers who have supported at least one mentee in their respective district between the 2013 and 2016 school years. Your participation in this research is voluntary, should you decide to participate.

\section{What can you expect during participation?}

If you agree to be in the study, you will be asked to participate in a focus group interview at your selective site. Each interview will be 30-45 minutes in length and will be voice recorded to help with the data collection process. At any time during the interview, you may skip answering a question. You may withdraw or refuse to participate in the research study without any penalty or loss of benefit to which you are otherwise entitled.

\section{Are there benefits or risks for participating in this study?}

There are no intended benefits or risks for participants in this survey. The research aims to benefit the school districts who participate during the dissemination of information phase following the completion of the study.

\section{How will responses be collected and shared?}

Your responses to the focus group interview questions will be collected and shared using pseudonyms to protect each participant.

\section{Questions:}

If you have questions, please contact Angela Boyer at 402-560-1867 at angelaboyer@mail.ozark.k12.mo.us or Dr. Jeffrey Cornelius-White at 417-836-6517 at jcornelius-white@missouristate.edu. The IRB Contact is 573-882-3181 or irb@missouri.edu. 


\section{Appendix F \\ Focus Group Questions}

1. Please describe your role as a mentor teacher. How long have you been a mentor teacher?

2. What led you to become a mentor teacher?

3. In your mentoring role, what opportunities, if any, for training have you received in your current district?

4. Describe the expectations, if applicable, for contact time with your mentee.

5. In what ways, if any, do you support your mentee with formative assessments?

6. Describe how you conduct classroom observations in your role as a mentor.

7. How frequently does a mentor program leader monitor your mentoring? What tools, if any, have been used to monitor your mentoring?

8. How has the monitoring of mentor programs in your district impacted your mentoring?

9. What elements of your current mentor program delivery are strengths of your district? Which elements could be improved?

10. Are there other aspects of your mentoring that you wished I would have asked about? 
VITA

Angela Boyer grew up in Omaha, Nebraska and started her career as an educator in Lincoln, Nebraska. She obtained a Bachelor's Degree in Elementary Education from the University of Nebraska- Lincoln followed by a Master's Degree in Curriculum and Instruction from Doane University. After spending eight years at Belmont Elementary as a classroom teacher and instructional coach, Angela moved to Ozark, Missouri to continue her education. She is currently a literacy coach for Ozark Schools and enjoys presenting professional development sessions. She and her husband live with their son in Ozark. 